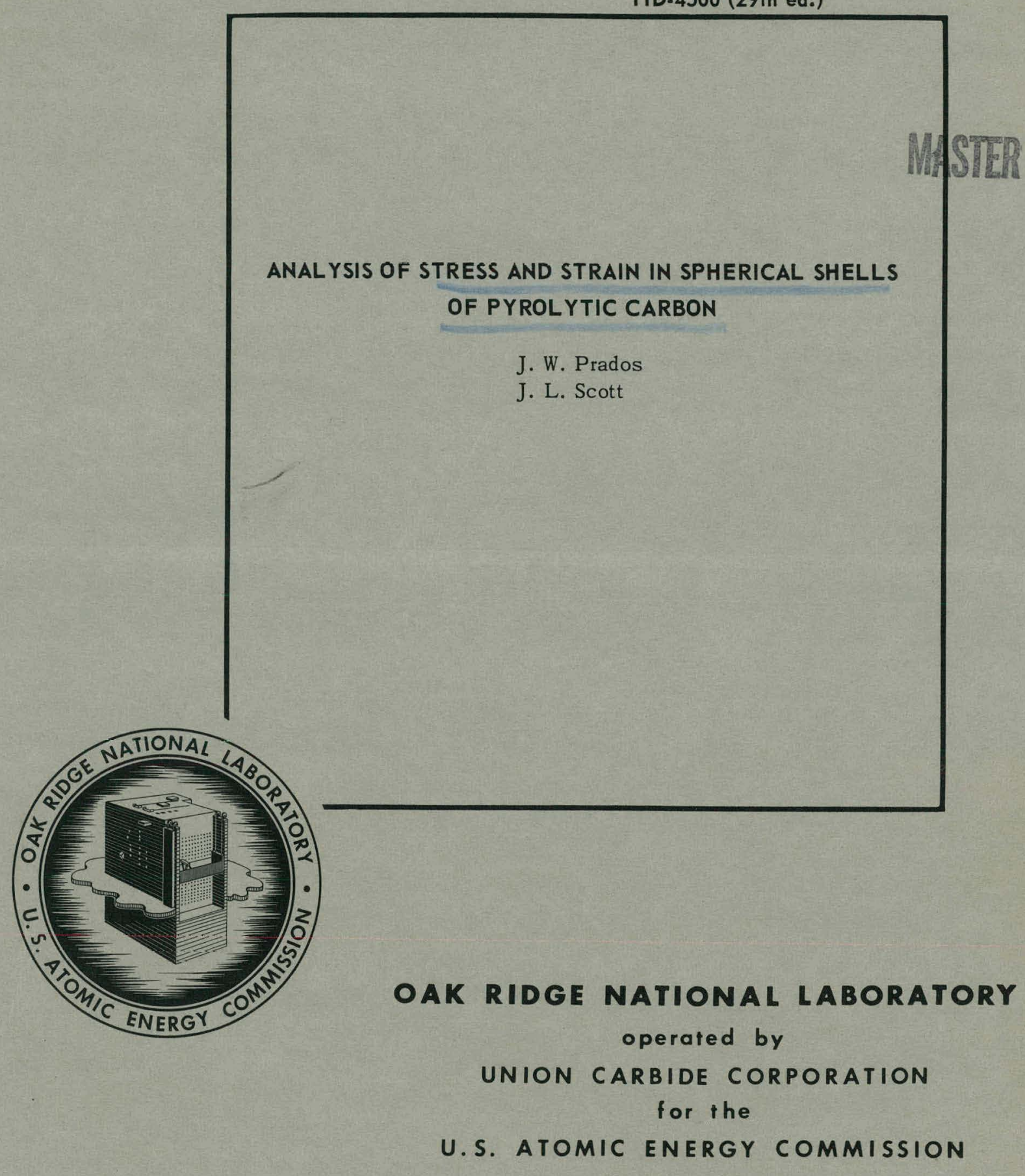




\section{DISCLAIMER}

This report was prepared as an account of work sponsored by an agency of the United States Government. Neither the United States Government nor any agency Thereof, nor any of their employees, makes any warranty, express or implied, or assumes any legal liability or responsibility for the accuracy, completeness, or usefulness of any information, apparatus, product, or process disclosed, or represents that its use would not infringe privately owned rights. Reference herein to any specific commercial product, process, or service by trade name, trademark, manufacturer, or otherwise does not necessarily constitute or imply its endorsement, recommendation, or favoring by the United States Government or any agency thereof. The views and opinions of authors expressed herein do not necessarily state or reflect those of the United States Government or any agency thereof. 


\section{DISCLAIMER}

Portions of this document may be illegible in electronic image products. Images are produced from the best available original document. 
Printed in USA. Price: $\$ 1.25$ Available from the

Office of Technical Services

U. S. Department of Commerce

Washington 25 , D. C.

\section{LEGAL NOTICE}

This report was prepared as an account of Government sponsored work. Neither the United States, nor the Commission, nor any person acting on behalf of the Commission:

A. Makes any warranty or representation, expressed or implied, with respect to the accuracy, completeness, or usefulness of the information contained in this report, or that the use of any information, apparatus, method, or process disclosed in this report may not infringe privately owned rights; or

B. Assumes any liabilities with respect to the use of, or for damages resulting from the use of any information, apparatus, method, or process disclosed in this report.

As used in the above, "person acting on behalf of the Commission" includes any employee or contractor of the Commission, or employee of such contractor, to the extent that such employee or contractor of the Commission, or employee of such contractor prepares, disseminates, or provides access to, any information pursuant to his employment or contract with the Commission, or his employment with such contractor. 
ORNL-3553

UC-25 - Metals, Ceramics, and Materials TID-4500 (29th ed.)

Contract No. W-7405-eng-26

METALS AND CERAMICS DIVISION

\section{ANAL YSIS OF STRESS AND STRAIN IN SPHERICAL SHELLS}

OF PYROLYTIC CARBON

J. W. Prados

J. L. Scott

JUNE 1964

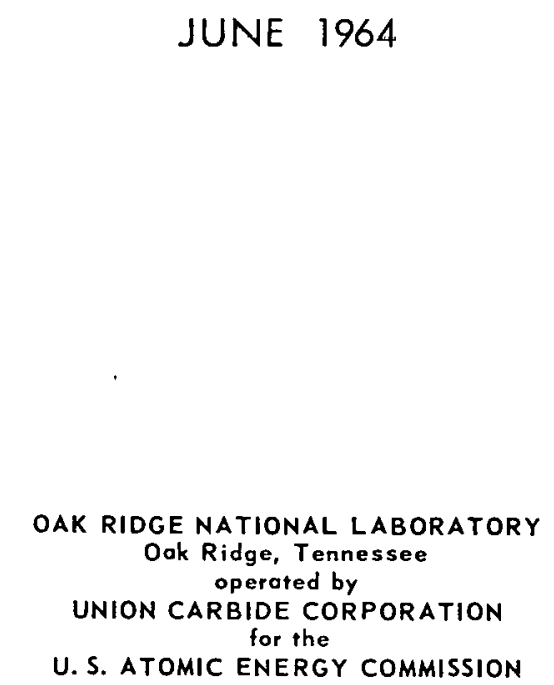


THIS PAGE

\section{WAS INTENTIONALLY LEFT BLANK}




\section{CONTENTS}

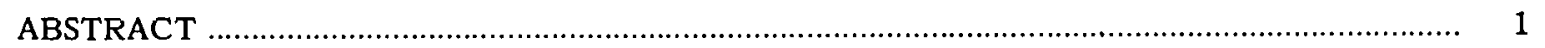

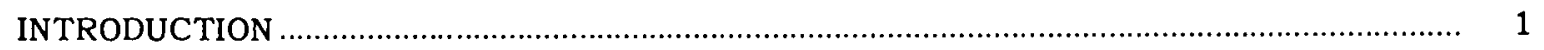

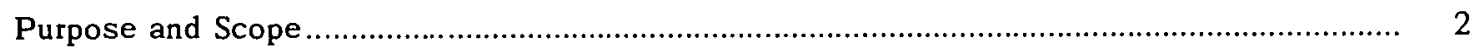

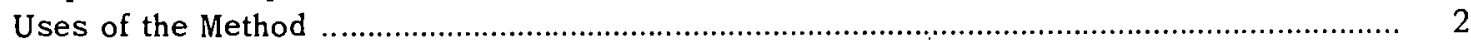

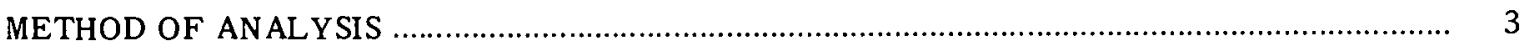

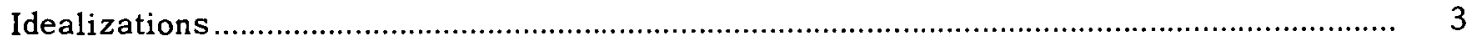

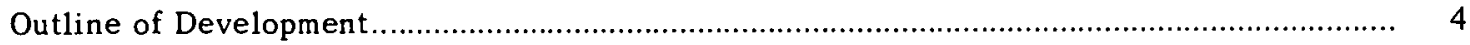

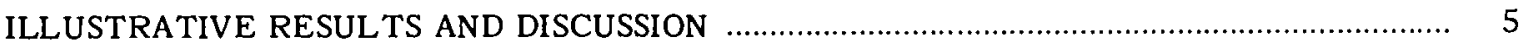

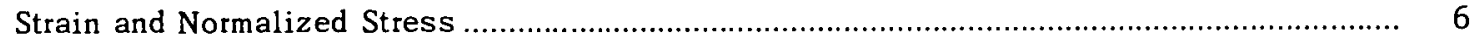

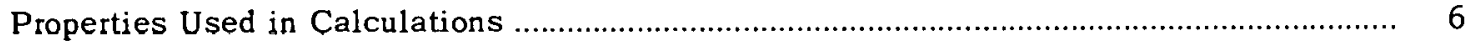

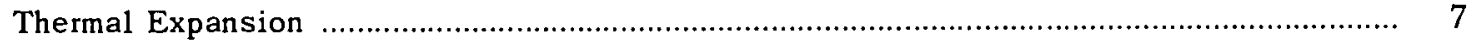

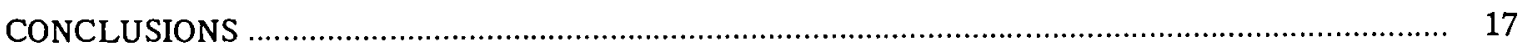

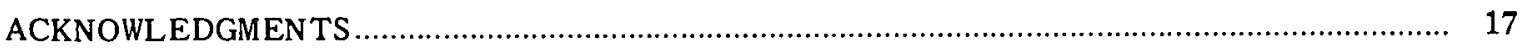

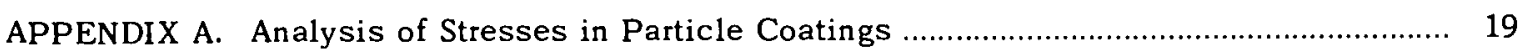

Anisotropic Behavior in Coating ............................................................................ 19

Isotropic Stress-Strain Relations with Anisotropic Expansion ..................................... 27

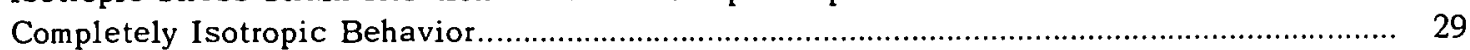

APPENDIX B. Pressure and Displacement Calculations ............................................ 31

APPENDIX C. Temperature-Drop Calculation for Coated Particle Under

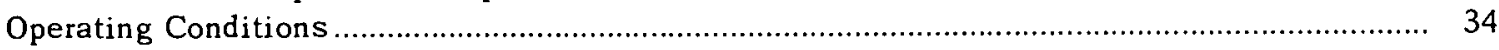

APPENDIX D. Computer Program "Stretch" for Calculating and Plotting Stress

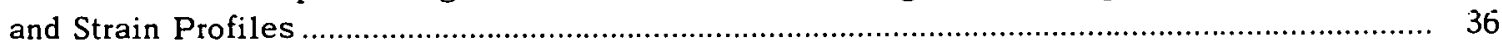

APPENDIX E. Reproduction of Computer Print-Out Sheet and Notation List ..........................44 


\title{
ANALYSIS OF STRESS AND STRAIN IN SPHERICAL SHELLS OF PYROLYTIC CARBON
}

\author{
J. W. Prados ${ }^{1} \quad$ J. L. Scott
}

\begin{abstract}
A technique was developed for calculating profiles of the tangential stress and strain components which occur in spherical pyrolytic carbon shells as a result of thermal expansion or radiation-induced dimensional changes. The method is based on a mathematical analysis of stress and strain in a spherically symmetric, anisotropic medium having hexagonal symmetry in which the crystallographic axes coincide with axes of geometrical symmetry. The results should be of value in the development of pyrolytic carbon-coated reactor fuel particles, particularly for the selection of optimum design parameters and for the planning and interpretation of failure tests.

A digital computer program was prepared for calculating tangential stress and strain profiles in particle coatings and plotting them as a function of position. The results of thermal stress calculations are presented for pyrolytic carbon coatings of three different thicknesses at temperatures below and above the deposition temperature.
\end{abstract}

\section{INTRODUCTION}

Pyrolytic carbon coatings applied to nuclear fuel particles for fission product retention must remain intact throughout a fuel element cycle if they are to fulfill their purpose. However, many factors in their operating environment produce internal stresses and strains within the coatings which may lead to premature failure. Among these factors are:

1. thermal expansion, resulting from differences in coating deposition temperature and operating temperature;

2. swclling of the core as fuel atoms are converted to fission products;

3. release of gaseous fission products from the fuel, leading to buildup of pressure between the fuel particle and the coating; and

4. dimensional changes in the coating itself, caused by fast-neutron or fission-fragment damage to the pyrolytic carbon.

A method for quantitatively predicting stresses and strains in the coatings produced by each of the above factors, acting singly and in combination, should be of value in the rational development

\footnotetext{
${ }^{1}$ Consultant from the University of 'lennessee.
} 
of coated-particle reactor fuels. Such a method would permit the coated-particle developer to select coating dimensions and properties to minimize the likelihood of failure during the fuel lifetime. It would further assist in the planning and interpretation of coated-particle tests.

\section{Purpose and Scope}

The object of this work was to develop a means of calculating both stress and strain in pyrolytic carbon coatings as functions of geometry, physical and mechanical properties, and operating

conditions. The present report provides the basic mathematical development and illustrates the use of the method through calculations of stress and strain profiles in coated particles resulting from thermal expansion alone. Future reports will present calculated stresses and strains resulting from combined thermal and radiation-induced changes in typical coated particles. It is hoped that such results may assist in interpreting failure of coated particles observed experimentally, in establishing coated-particle failure criteria, and in defining safe operating limits for coated-particle fuel elements.

In the absence of published failure criteria for pyrolytic carbon and the unknown manner in which radiation might affect such criteria, no attempt has been made to consider failure quantitatively in this portion of this study. The results are presented in a convenient form for relating failure to maximum tensile stress or maximum tensile strain. The general methods developed would permit calculations of maximum shear stress or strain as well, although some additional manipulations and computations would be required.

\section{Uses of the Method}

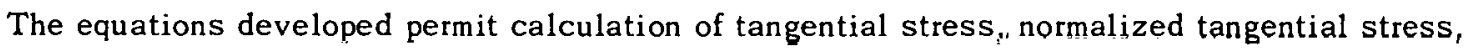
and tangential strain components as functions of radial position in pyrolytic carbon coatings. The results are sufficiently general to permit investigation of a number of different stress-inducing factors, acting singly and in combination, as well as the effects of changes in geometrical and physical properties of the coated particles on the coating stresses and strains. In particular, the following stress-inducing factors can be incorporated into the calculations:

1. anisotropic expansion or contraction within the coating, resulting from:

a. differences between actual coating temperature and the temperature at which it.was deposited, or

b. dimensional changes caused by fast-neutron damage;

2. forces acting on the inner coating surface from:

a. swelling of the fuel particle against the coating due to differential thermal expansion or volume changes from fission, or

b. buildup of fission-gas pressure in the void space between the fuel particle and the coating; 
3. radially dependent expansion or contraction, resulting from:

a. temperature gradients across the coating, or

b. fission-fragment damage to the inner layer of the coating; and

4. combinations of any or all of the above effects.

A computer program for calculation of stress and strain profiles resulting from factors of types 1 and 2 above, acting singly or in combination, has been developed. As discussed in the section on "Illustrative Results and Discussion," factors of type 3 were not incorporated in the program, although modifications to include them could be added. Use of the program permits investigation of the effect of a number of parameters on coating stress and strain profiles. Those which can be treated conveniently are:

1. dimensions of the coated particle, such as fuel-particle radius, coating thickness, and thickness and porosity of the gap, if any, between the coating and the fuel particle;

2. physical properties of the coating and fucl core, such as thermal expansion coefficients, Young's moduli, Poisson's ratios (in directions both normal and parallel to the surface of the spheroidal fuel particle); and

3. operating conditions of the coated particle, including temperature and radiation history.

\section{METHOD OF ANALYSIS}

\section{Idealizations}

The most serious idealizations employed in the present analysis are the assumptions (1) that the fuel particles are spheres with the coatings spherically symmetrical shells, and (2) that the pyrolytic carbon coatings exhibit elastic behavior. Irregular coating geometry may well lead to concentrations of stress considerably more severe than predicted by the theory. Nonlinear elastic behavior and creep (which should be more pronounced at higher temperature), on the other hand, will tend to provide actual stresses lower than those predicted. Errors introduced by these two idealizations would, therefore, be in opposite directions, although cancellation for any given case would be fortuitous.

A major idealization which has not been made in this work is the assumption of isotropic behavior in the pyrolytic carbon coating. Since the axes of geometrical symmetry of the system will, in general, coincide with the principal hexagonal crystal axes of the coating (c, or perpendicular, crystal axis lies along sphere radii, with hexagonal layer planes along concentric spherical shells), one can account for differences in physical properties of anisotropic pyrolytic carbon without hopelessly complicating the mathematical treatment. As will be shown in the example calculations, results which account for these anisotropic effects may differ markedly from those calculated under the assumption of isotropic behavior. 
In practice, the reliability of the calculations is further limited by lack of accurate physical and mechanical property data for pyrolytic carbon coatings and fuel materials. Properties of the coatings in particular are markedly dependent on manufacturing techniques, and properties measured for one batch of material may be grossly different from those for another. ${ }^{2,3}$ Due to lack of data on the effect of orientation on elastic properties, the calculations were performed under the assumption of equal elastic moduli and Poisson's ratios in the crystallographic $c$ direction and in basal planes. It is felt that the uncertainty introduced by this idealization is less than that in the actual numbers used; the general calculation method will permit this assumption to be relaxed when more accurate data become available. The important anisotropic effects in thermal expansion and radiation-induced dimensional changes are retained in the calculations.

Physical property data used in the calculations were taken from refs 2 and 3 and were measured for General Electric and Raytheon pyrolytic carbons deposited from methane at relatively low rates near $2100^{\circ} \mathrm{C}$. The resulting products were highly oriented with a density near theoretical (2.2 $\mathrm{g} / \mathrm{cm}^{3}$ ). It is recognized that the properties of pyrolytic carbon deposited on small (approximately $200 \mu$ ) particles in a fluidized bed may be substantially different from those of massive pyrolytic carbon. Property data for such coatings, however, are not yet available.

\section{Outline of Development}

The development of mathematical relations for calculating coating stresses and strains is presented in Appendix A and is given here only in verbal outline with references to key equations in the appendix where appropriate. The effect of system parameters on results is illustrated in a later section of this report through graphical comparisons of the results of a series of calculations.

The major effects of interest in these calculations are the tangential or "hoop" stresses and strains in the pyrolytic carbon coatings. These effects may be understood from a combined analysis of the coating and fuel core. The general methods of thermal stress analysis, ${ }^{4}$ modified to include the anisotropic effects, can be applied to each region separately and the solutions joined at the fuel-coating interface. The equations required are:

1. the equilibrium force balance for a region of spherical symmetry, Eq. (1), Appendix A; and

2. relations between stress, strain, displacement, and expansion for an anisotropic material with hexagonal crystal symmetry, Eqs. (4) through (12), Appendix A.

Algebraic manipulation of these relationships leads to a differential equation for the displacement of a point in the coating or fuel as a function of radial position, Eq. (20), Appendix A. The equation may be integrated analytically for the coating to give solutions for displacement, stress, and

\footnotetext{
${ }^{2}$ J. Pappis, R. Donadio, and L. Hagen, The Mechanical Properties of Pyrographite, Tech. Memo. T-216, Raytheon Corp., Waltham, Mass. (March 1960).

3"Pyrolytic Graphi te Preliminary Engineering Data," General Electric Co., Detroit, Mich. (no date).

${ }^{4}$ S. Timoshenko and J. N. Goodier, Theory of Elasticity, pp 416-21, McGraw-Hill, New Y ork, 1951.
} 
strain as a function of radius, Eqs. (26) through (31), Appendix A. These solutions contain two arbitrary constants of integration which must be evaluated from boundary conditions on the coating. If it is assumed that the outer surface of the coating is unconstrained so that the radial stress component vanishes at the boundary, the constants may be expressed in terms of the displacement of the inner coating surface alone.

A similar treatment of the fuel core region (here assuming fully isotropic behavior) leads to solutions for displacement, stress, and strain as functions of radial position.

To complete the solution, one must find the displacements of the inner coating surface and outer fuel surface. The method employed depends on which of two possible conditions exists:

1. the fuel and coating remain in contact, in which case both displacement and radial stress components must be equal on each side of the fuel-coating interface; or

2. the fuel and coating are not in contact, in which case the radial stress components at the outer fuel and inner coating surfaces must equal the negative of the fission-gas pressure in the space between.

For condition 1, the solution for fuel and coating displacement is given by Eq. (50), Appendix A; for condition 2, the coating displacement is given by Eq. (38), Appendix A. The final results for tangential stress and strain components are given by Eqs. (53) and (54), Appendix A.

Simplification of these results is possible for a number of special cases. If the elastic moduli and Poisson's ratios are assumed to be equal in both crystal directions in the coating, tangential stress and strain components may be calculated from Eqs. (53a) and (54a), Appendix A; if, in addition, it is assumed that all dimensional-change-inducing factors (e..g., temperature, radiation damage) do not change with radial position, simpler equations, Eqs. $(53 b)$ and $(54 b)$, may be employed. Finally, if the coating is assumed to be fully isotropic, with regard to dimensional-change factors as well as elastic constants, F,qs. (53c) and (54c) or (53d) and (54d) apply.

Special problems arising in the calculation of fission-gas pressure where a gap exists between the fuel particle and the coating are discussed quantitatively in Appendix B.

\section{ILLUSTRATIVE RESULTS AND DISCUSSION}

Although the calculation methods developed permit investigation of a variety of stress-inducing causes, only thermal stress and strain are considered in the illustrative calculations to be presented here. In future studies, the method will be applied to coated particles operating under reactor conditions where combined environmental causes are important.

As previously stated, calculations were performed under the assumption that the elastic constants in the coating were isotropic, while retaining the anisotropy of the thermal expansion and radiation-induced dimensional changes. For comparison, one set of calculations was also performed under the assumption of fully isotropic behavior in the coating. Though not a basic requirement of the method, it was assumed that the temperature and radiation factors were independent of radial position. This assumption is felt to be well justified for the present calculations: sample heat 
transfer calculation for a typical coated particle indicated temperature drops across the coating should be below $10^{\circ} \mathrm{C}$ (see Appendix C).

The stress and strain calculations were programmed for the CDC 1604-A digital computer at ORNL and were executed on this machine. Computed results were plotted automatically on the Calcomp plotter. The program is available under the name STRETCH; its general form and use are described in Appendix D.

\section{Strain and Normalized Stress}

There appears to be some disagreement in the use of the word "strain" in the presence of volume changes, as in thermal expansion. If one defines a normal strain component as a total change in length per unit initial length, it is possible to have strain in a system with no corresponding stress (as, for example, in a uniformly heated, unconstrained rod). In the present work, the total change in length per unit initial length is designated as "total fractional elongation"; the term "strain" is reserved for that part of the fractional elongation associated with a stress. Relations between these two quantities are given in Eqs. (7) through (10), Appendix A.

Test calculations have indicated that computed strains are somewhat insensitive to the value of Young's modulus assumed for the pyrolytic carbon coating. This insensitivity results, to a large degree, from the low values of Young's modulus for pyrolytic carbon compared with the values for fuel core materials $\left[\mathrm{UC}_{2}\right.$ and $(\mathrm{Th}, \mathrm{U}) \mathrm{C}_{2}$ ] and is fortunate since Young's moduli for pyrolytic carbon are not accurately known and vary widely from sample to sample. Computed stresses, on the other hand. are almost directly proportional to the Young's modulus value assumed. Hence, in the present illustrations, absolute stress values are not plotted, but rather a normalized tangential stress, equal to the actual tangential stress, multiplied by one minus Poisson's ratio for the coating and divided by the Young's modulus. This normalized stress shows the same radial variation as the actual stress and arises naturally in the equation relating tangential strain, tangential stress, and radial stress components, Eq. (4), Appendix A.

A sample computer printout sheet giving tabulated results for one case considered is presented in Appendix E. In the tabulations, actual as well as normalized tangential stress values are given.

\section{Properties Used in Calculations}

The following physical properties were used in all calculations. Fuel properties were taken as those of $\mathrm{UC}_{2}$ from ref 5 . Pyrolytic carbon properties were obtained from refs 2 and 3 , as previously discussed.

${ }^{5}$ R. W. Endebrock (ed.), Properties of Fuels for High-Temperature Reactor Concepts, BMI-1598 (November 1962). 


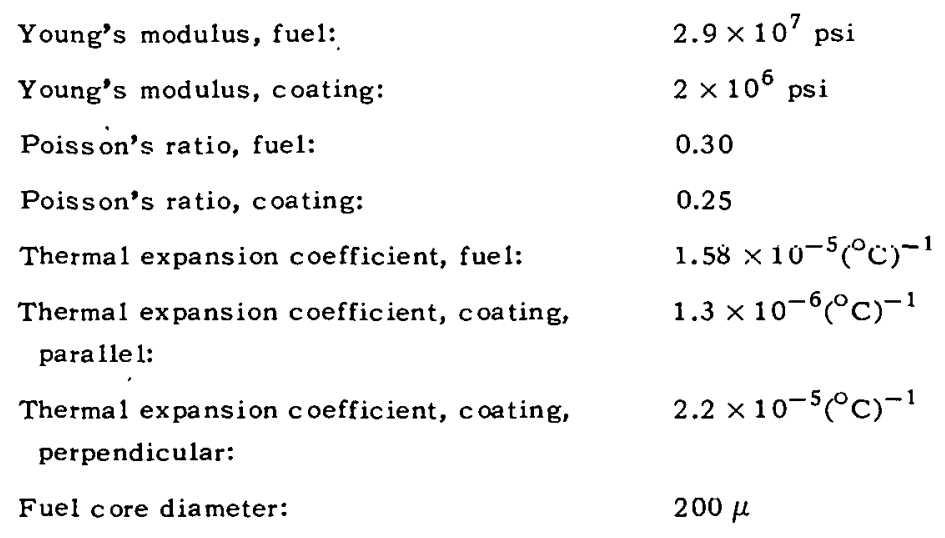

Additional quantities required for the calculations are presented with the individual results.

\section{Thermal Expansion}

In anisotropic pyrolytic carbon coating, thermal stresses may be set up at temperatures different from that at which the coating was applied even though the temperature is uniform throughout the particle. Additional stresses may be produced if the coated particle is heated above its fabrication temperature and the fuel core tends to expand more than the coating. These effects are demonstrated and compared for three types of coating at each of three temperatures. Coating types considered are:

1. $100-\mu$ thickness, initially in contact with the fuel core,

2. $95-\mu$ thickness, with a $5-\mu$ initial gap between core and coating, and

3. $50-\mu$ thickness, with a $50-\mu$ initial gap between core and coating.

Temperatures employed were $1800^{\circ} \mathrm{C}$ below deposition temperature, $400^{\circ} \mathrm{C}$ above deposition temperature, and $800^{\circ} \mathrm{C}$ above deposition temperature,

To show the effect of anisotropy on the results, calculations were performed for an isotropic coating of type 1 above at each of the three temperatures. A volumetric mean thermal expansion coefficient was used for the pyrolytic graphite, equal to two-thirds the coefficient in the parallel crystal direction plus one-third the coefficient in the perpendicular direction.

Tongential Strain. - Calculated tangential strain profiles are shown in Figs. 1 through 4 for the above cases. In each plot, the 0.0 on the horizontal axis coincides with the inner surface of the coating and the 1.0 coincides with the outer surface. Curve parameters (DELTA T) are differences between the actual coated-particle temperature and the temperature at which the coating was deposited. It was assumed that no strain existed at the deposition temperature. Features of the plots which should be noted are:

1. For unconstrained coatings (no contact with the fuel particle), thermal strain is compressive (negative) on the inner surface and tensile (positive) on the outer surface at temperatures above the depusition temperature. Below the deposition temperature, this effect is reversed. 


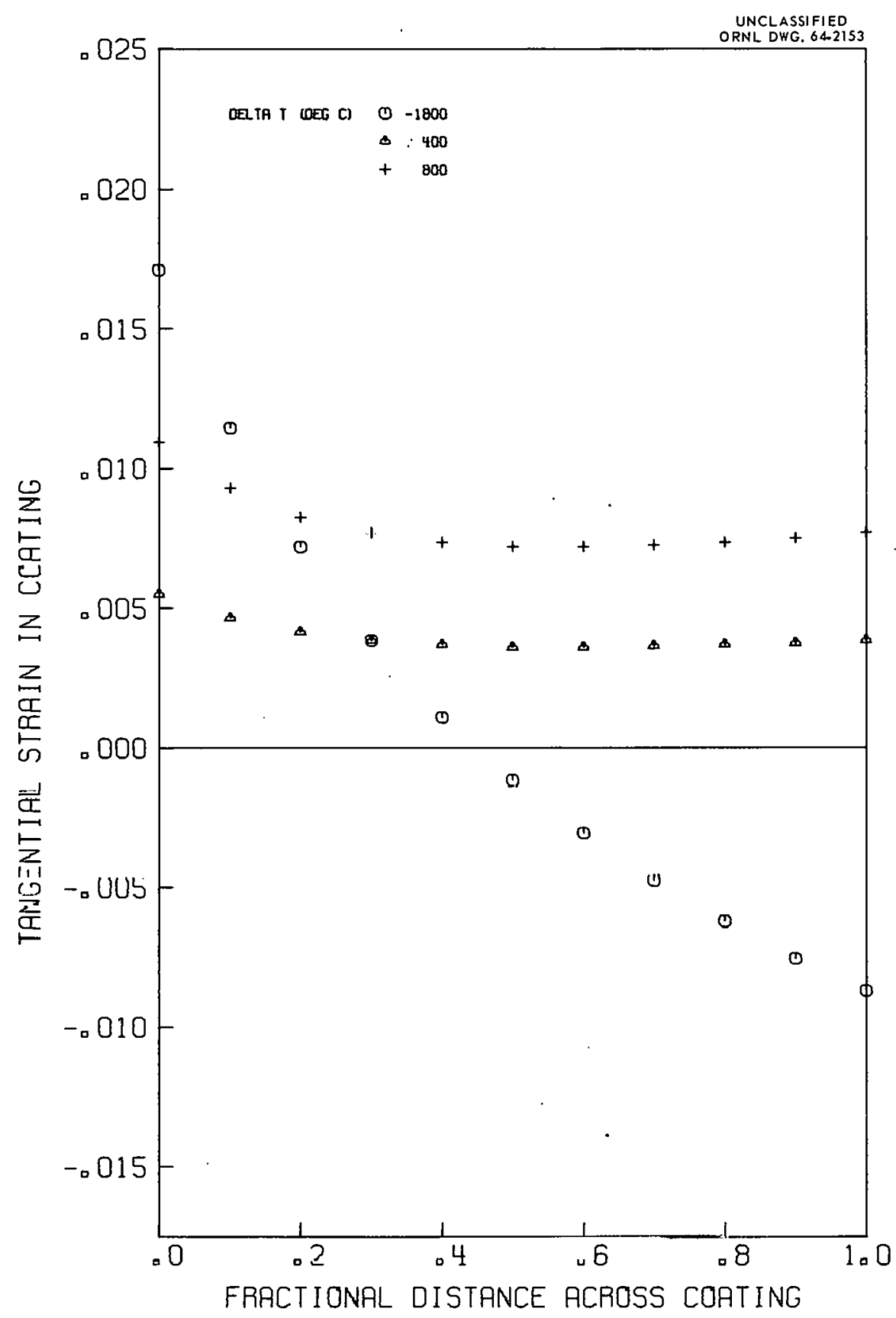

Fig: 1. Tangential Thermal Strain Profiles in Pyrolytic Carbon Coating: $100-\mu$ Coating, No Initial Gap. 


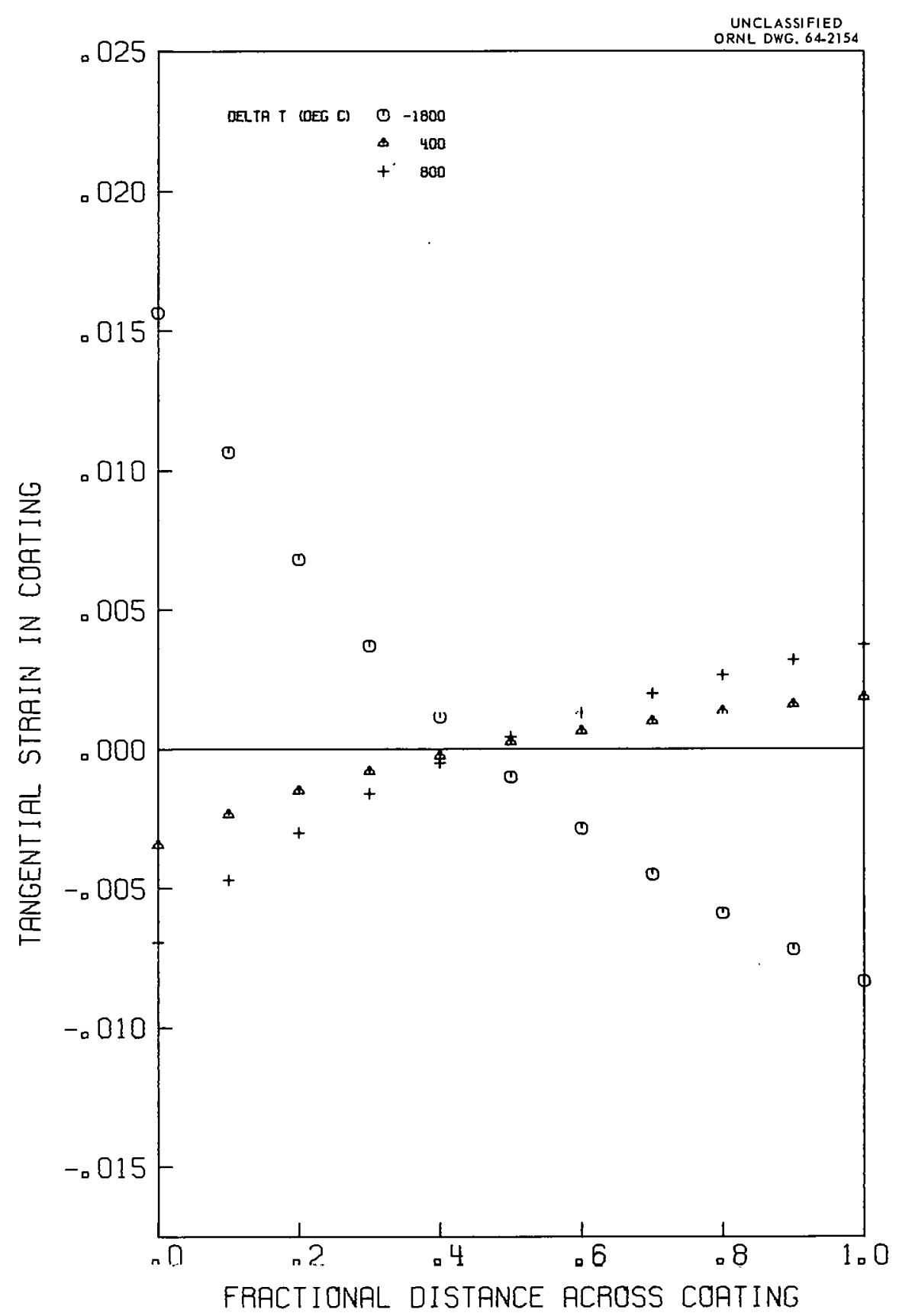

Fig. 2. Tangential Thermal Strain Profiles in Pyrolytic Carbon Coating: 95- $\mu$ Coating, $5-\mu$ Initial Gap. 


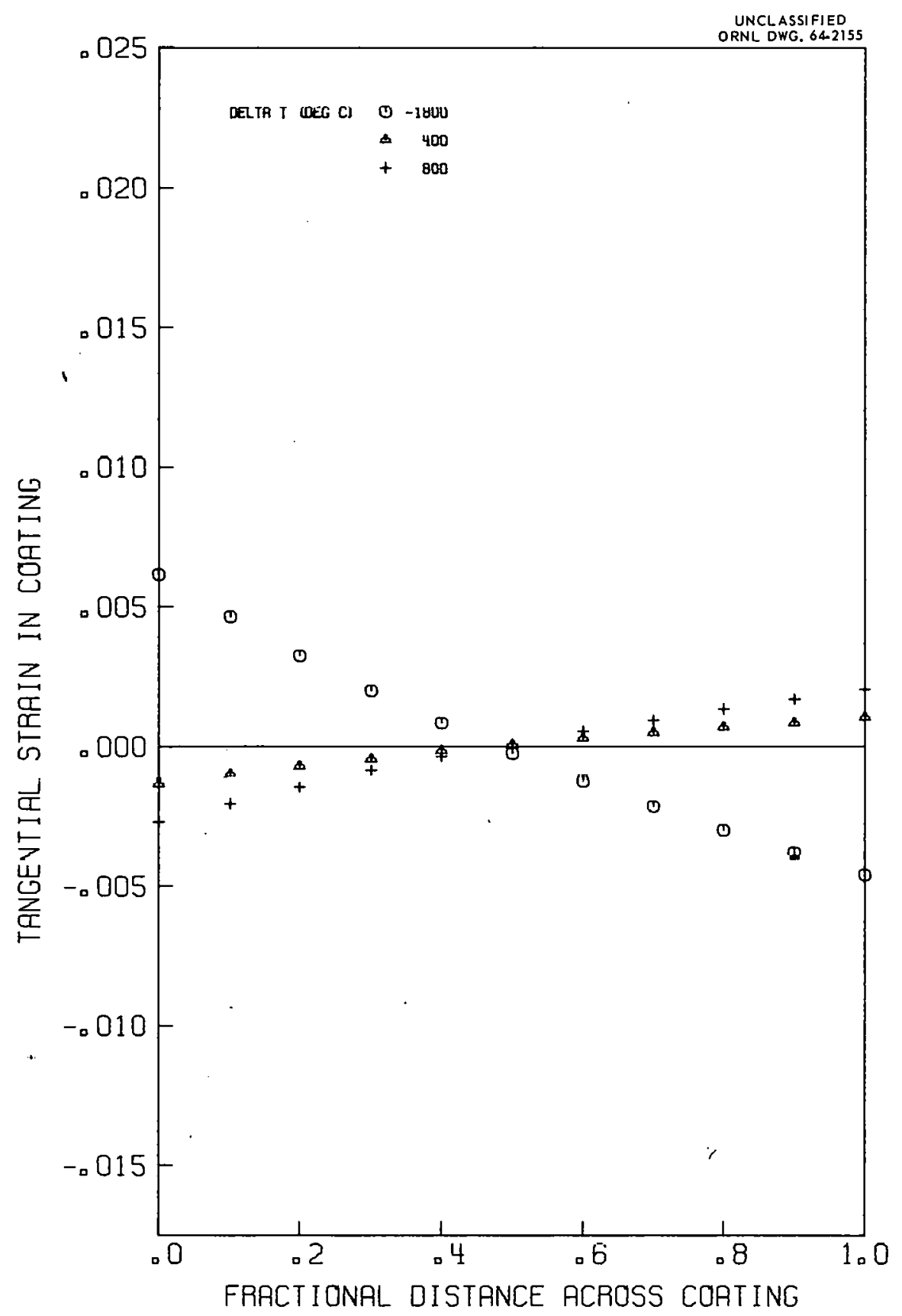

Fig. 3. Tangential Thermal Stroin Profiles in Pyrolytic Carbon Coating: 50- $\mu$ Coating, 50- $\mu$ Initial Gop. 


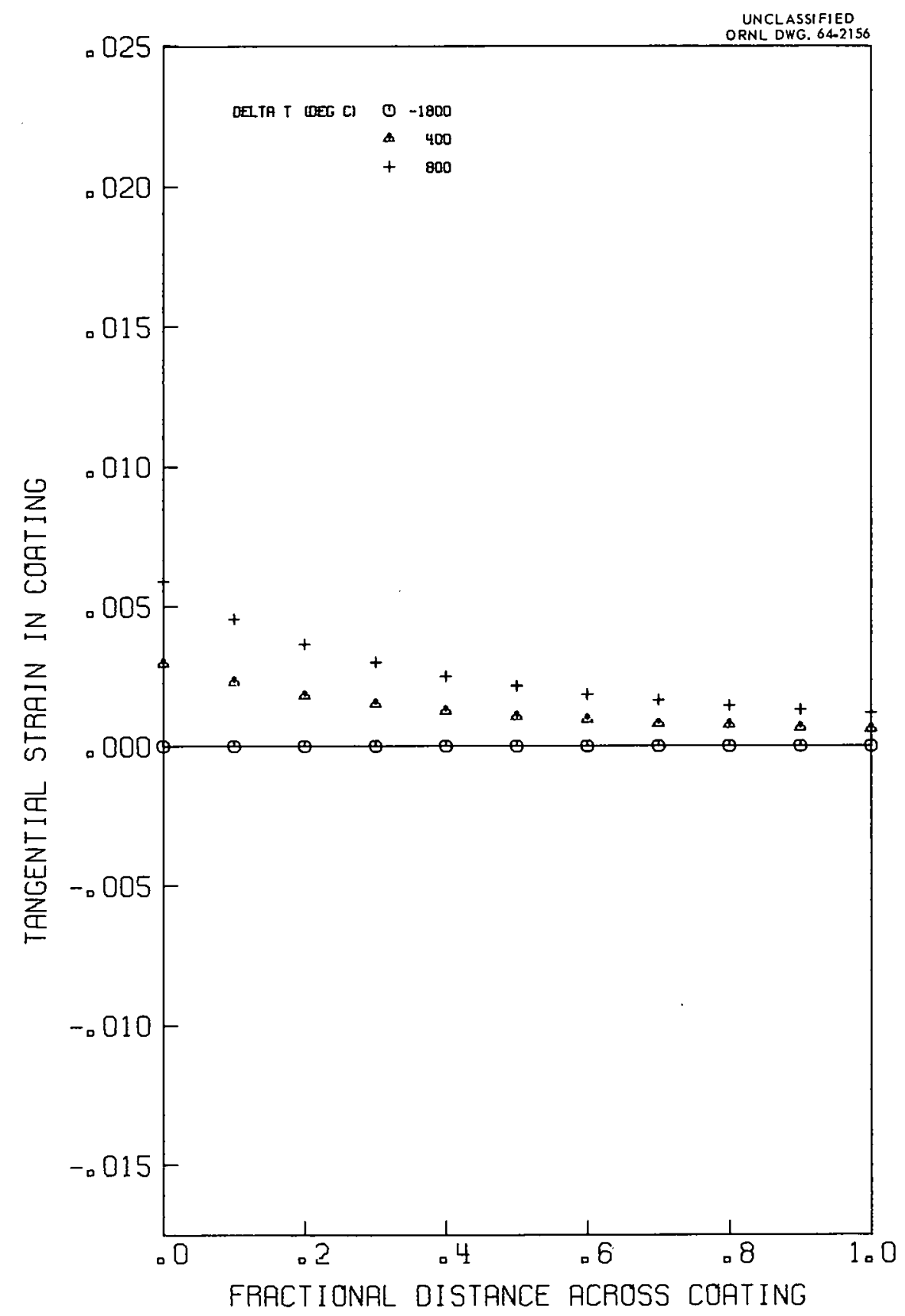

Fig. 4. Tangential Thermal Strain Profiles in Pyrolytic Carbon Coating: 100- $\mu$ Coating, No Initial Gap, Isotropic Case. 
2. For cases where contact is maintained between fuel particle and coating, thermal strain is tensile throughout and may be slightly greater at the inner surface.

3. With the expansion coefficients employed in the present example, the fuel particle shrinks away from the coating below fabrication temperature; hence, results for the $100-\mu$ coating with no initial gap are almost identical with those for the $95-\mu$ coating with an initial gap, since in either case there is no constraint on the inner surface on cooling.

4. The thin $(50-\mu)$ coating shows lower thermal strain than the thicker $(95-\mu)$ coating both on heating and cooling even though both are unconstrained.

5. Strains calculated on the assumption of isotropic expansion in the coating are significantly smaller than those where anisotropic expansion is taken into account; the only strain-producing factor in the isotropic case is the differential expansion of core and coating. Where the coating and core do not maintain contact, as on cooling, no strain exists.

As a final comment, it might be noted that in the isotropic case the strains are a maximum at the inner surface of the coating. This may be seen from the isotropic reduction of the relation for calculation of strain, Eq. (53d), Appendix A. No such generalization is possible in the anisotropic case; maximum strain can occur at either the inner or outer boundary, and at times the curves exhibit a minimum within the coating.

In general one may consider the tangential strains in the coating as the sum of two effects: (1) strain resulting from anisotropic expansion of the coating, which arises whether or not the inner surface is constrained; and (2) strains arising from differential expansion of the fuel particle against the coating, which exists only if contact between fuel and coating is maintained. Strains of type 1 are represented by the second and third terms in Eq. (54b), Appendix A, and are absent in isotropic materials. Strains of type 2 are represented by the first term in Eq. (54b) and exist only when a radial stress is applied on the inner surface of the coating for isotropic or anisotropic materials.

Tangential Stress. - Profiles of the normalized tangential component of thermal stress are shown in Figs. 5 through 8 for the same cases illustrated in Figs. 1 through 4 . It can be seen that the stress curves exhibit the same general shape as those of strain. As can be seen from Eq. (4), Appendix $\mathrm{A}$, the tangential strain and normalized tangential stress components differ only by a term involving the radial stress component. The tangential strain and normalized tangential stress must be numerically equal at the outer coating boundary, since radial stress is assumed to vanish on this surface. They will also be equal on the inner coating boundary, provided that the coating does not maintain contact with the fuel particle and that no fission-gas pressure exists in the gap between. In the case where contact is maintained, the tangential strain is always greater at the inner boundary than the normalized tangential stress, since the radial stress is negative (compressive) at this point and the term in which it appears is subtracted from the tangential stress term in Eq. (4), Appendix $A$. 


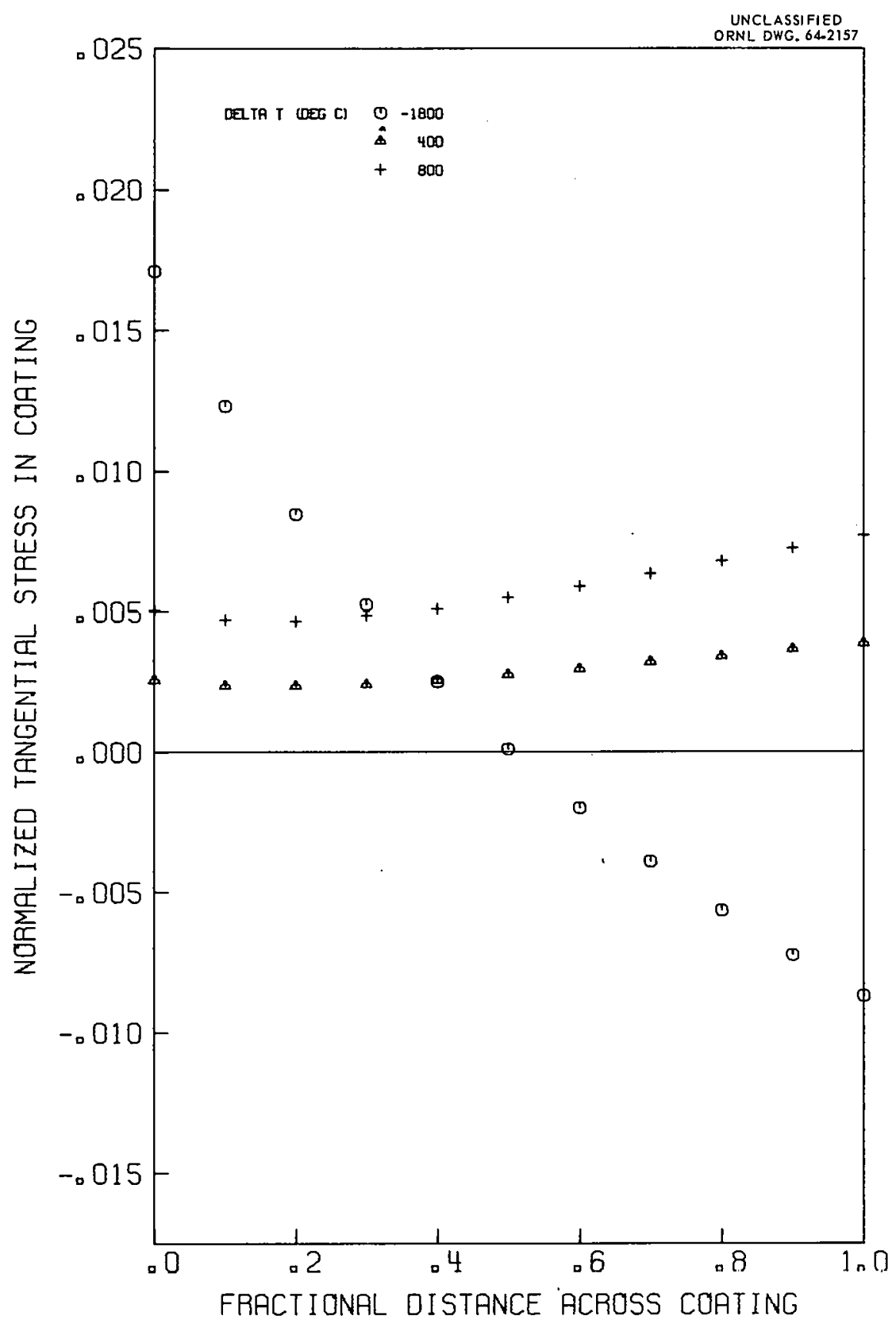

Fig. 5. Normalized Tangential Thermal Stress Profiles in Pyrolytic Carbon Coatings: $100 \mu$ Coating, No Initial Gap. 


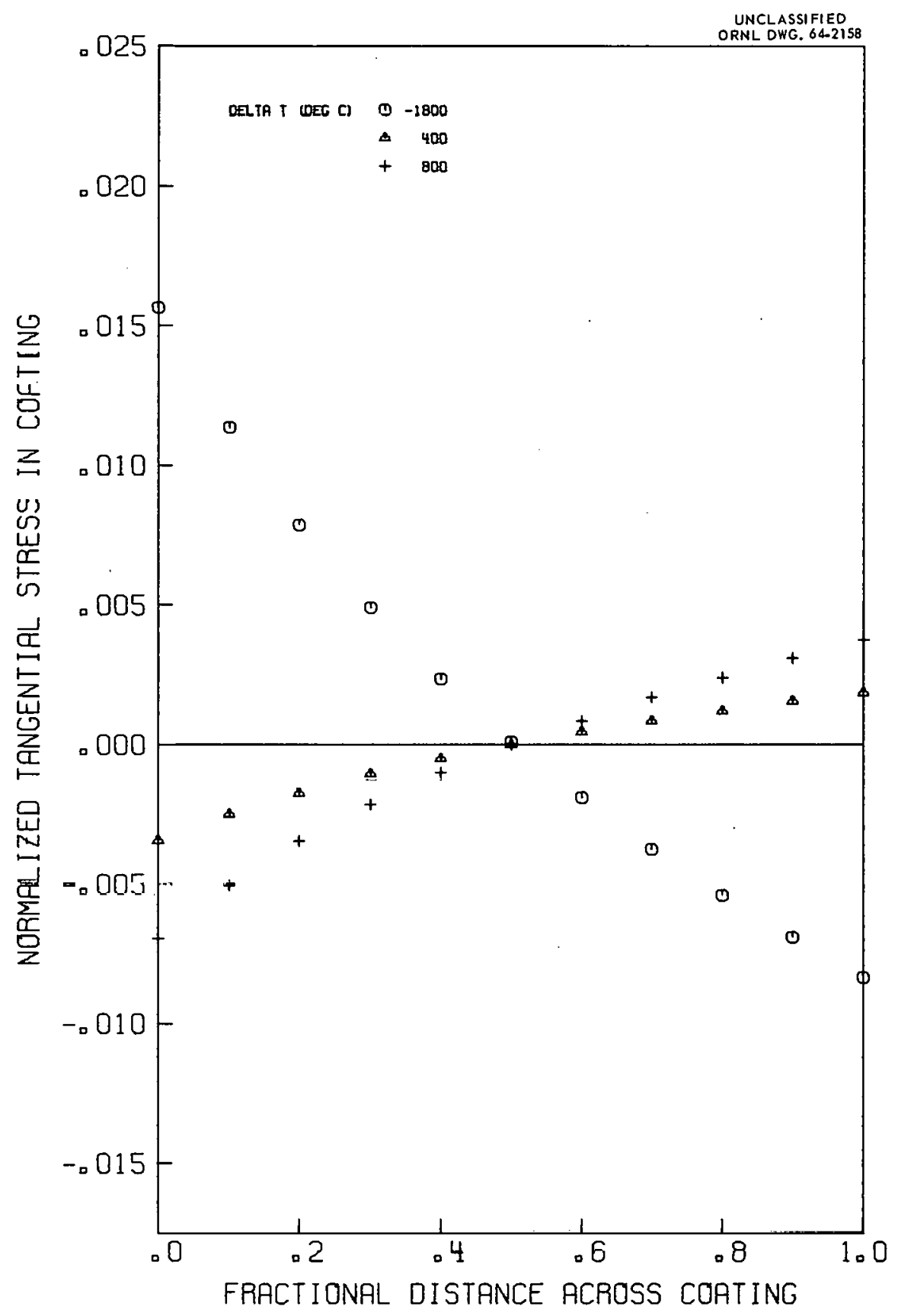

Fig. 6. Normalized Tangential Thermal Stress Profiles in Pyrolytic Carbon Coatings: $95-\mu$ Coating, 5- $\mu$ Initial Gap. 


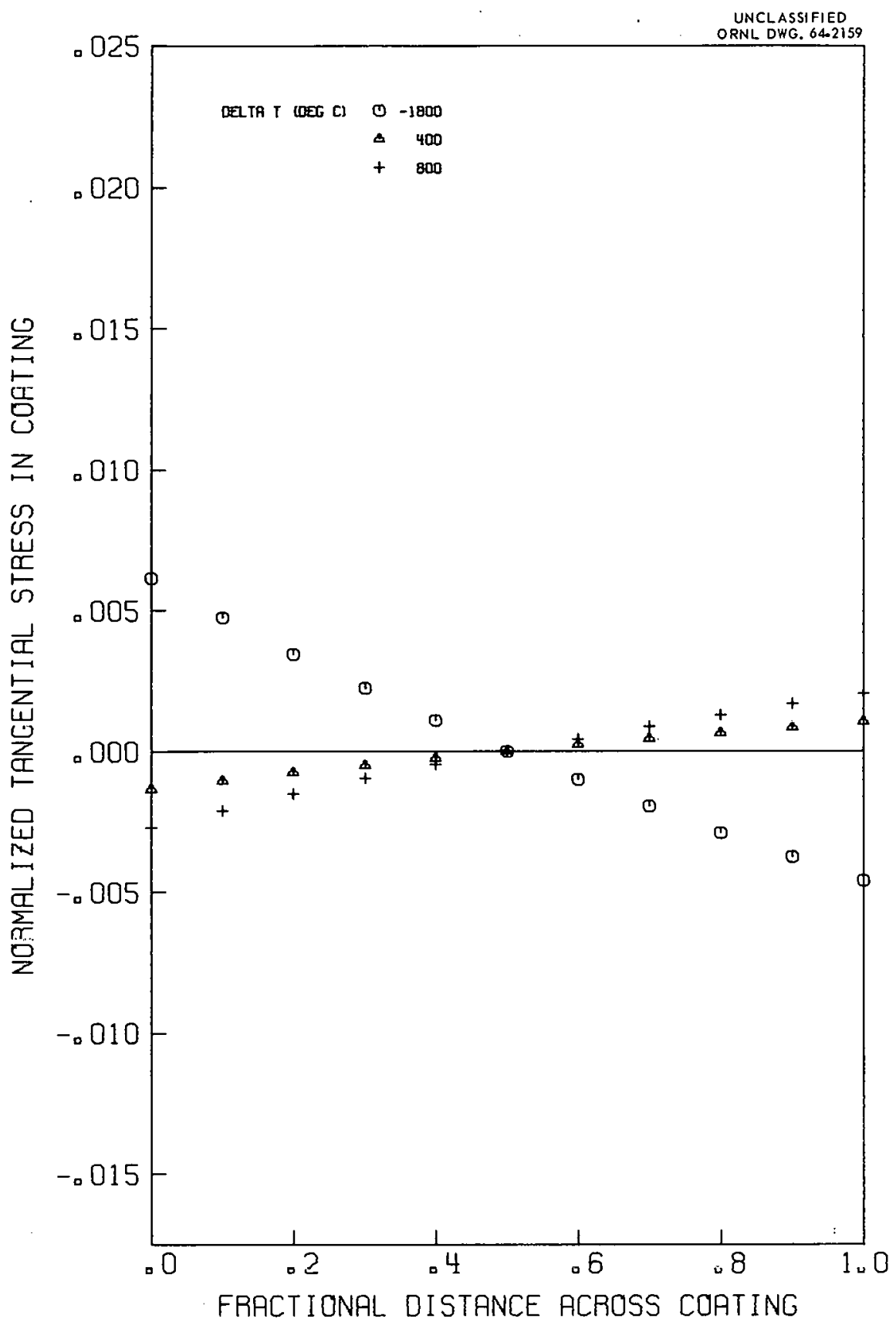

Fig. 7. Normalized Tangential Thermal Stress Profiles in Pyrolytic Carbon Coatings: $50-\mu$ Coating, 50- $\mu$ Initial Gap. 


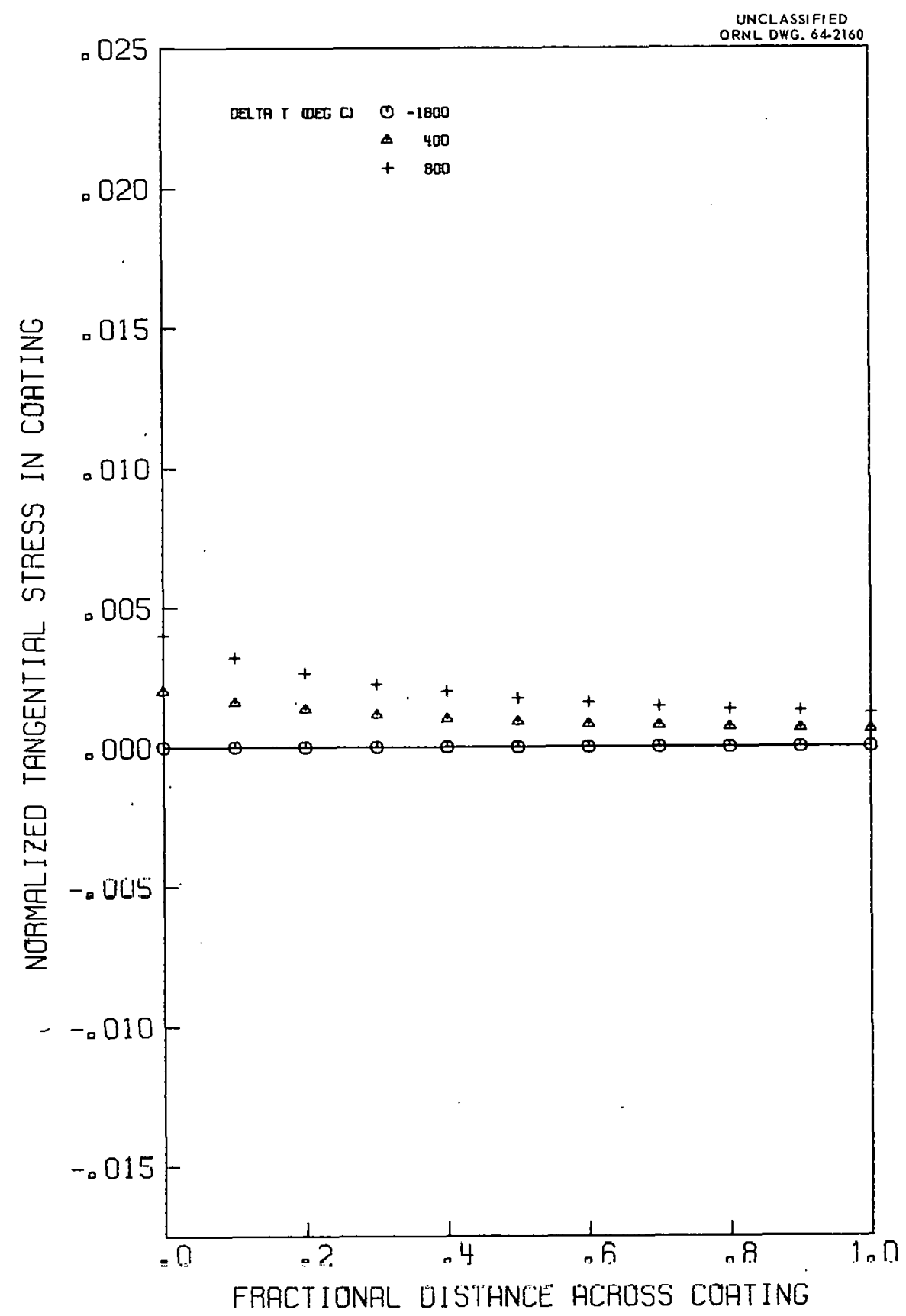

Fig. 8. Normalized Tangential Thermal Stress Profiles in Pyrolytic Corbon Coatings: 100 $\mu$ Coating, No Initial Gap, Isotropic Case. 


\section{CONCLUSIONS}

A means has been devised for quantitative calculation of tangential stress and strain profiles in spherical pyrolytic carbon coatings on reactor fuel particles. The method can account for the anisotropic nature of the coating material as well as for radial variations in expansion effects in the coating and fuel particle.

The assumptions employed in the present mathematical model are believed to be reasonable, but have not been subjected to a critical experimental test. Because of this, as well as the present uncertainty and variability in pyrolytic carbon properties, absolute numbers calculated by this method should be used with caution until (1) more complete characterization and property data become available for pyrolytic carbon, and (2) predicted coated-particle failure conditions based on independent failure criteria for pyrolytic carbon can be verified by experiment. Even now, however, relative comparisons of behavior should be quite meaningful and should be of considerable assistance in the selection of optimum coated-particle design parameters and test conditions.

Illustrative calculations of thermal stress and strain in particle coatings of various designs demonstrated the marked effects of coating anisotropy and dimensions on the stresses set up by given thermal conditions.

\section{ACKNOWLEDGMENTS}

The authors would like to express their thanks to $W$. O. Harms for providing valuable information on the nature and properties of coated particles and to $C$. Michelson for his key advice in the preparation and debugging of the computer program. 
THIS PAGE

\section{WAS INTENTIONALLY LEFT BLANK}




\section{Appendix A}

\section{ANALYSIS OF STRESSES IN PARTICLE COATINGS}

\section{Anisotropic Behavior in Cooting}

Stress and strain in a spherical particle coating caused by thermal expansion, swelling of the fuel core, or radiation damage in the coating are analyzed under the following assumptions:

1. the coating is spherically symmetrical about the core,

2. the outer surface of the coating is not constrained,

3. fuel and coating deform elastically,

4. the fuel core is isotropic, and

5. elastic properties are constant within coating and fuel.

Examination of the pyrolytic carbon coatings ${ }^{6}$ indicates that in many coatings the hexagonal layer planes lie in concentric spherical shells while the $c$ (perpendicular) crystallographic axis lies in the radial direction. Hence the axes of crystal symmetry coincide with the geometrical symmetry of the coated particle.

The equation of equilibrium for a spherically symmetrical system is: ${ }^{7}$

$$
\frac{d \sigma_{r}}{d r}+\frac{2}{r}\left(\sigma_{r}-\sigma_{\theta}\right)=0
$$

where

$\sigma_{\theta}=$ normal stress in the tangential direction,

$\sigma_{r}=$ normal stress in the radial direction,

$r=$ radial distance from center of sphere.

With reference to the spherical coordinates, $r, \theta, \phi$, it will be noted that, as a consequence of the symmetry, the $\theta$ and $\phi$ directions are indistinguishable, and no variations occur in these directions. Further, no shear stresses act on the "constant $r$ " or "constant $\theta$ " surfacer.

To relate the stresses and strains in a hexagonal crystal, five elastic constants are required. ${ }^{8}$ If there is a tendency for expansion or contraction to occur due to temperature changes or radiation damage, at least two additional parameters must be introduced. ${ }^{9}$ The elastic constants may be expressed as compliances ${ }^{8}$ or, by analogy with isotropic materials, by Young's moduli and Poisson's

${ }^{6}$ C. K. H. DuBose and R. J. Gray, Metallographic Examination of Pytolytic-Carbon Coated and Uncoated Uranium Carbide Patticles, ORNL-TM-521, pp 38-39 (June 25, 1963)。

${ }^{7}$ S. Timoshenko and J. N. Goodier, Theory of Elasticity, p 359, McGraw-Hill, New Y ork, 1951.

${ }^{8}$ J. F. Nye, Physical Properties of Crystals, pp 131-49, Clarend on Press, Oxford, 1957.

9 J. F. Nye, Physical Properties of Crystals, pp 106-9, Clarendon Press, Oxford, 1957. 
ratios. In terms of the compliance constants

$$
\begin{gathered}
e_{\theta}=\left(s_{11}+s_{12}\right) \sigma_{\theta}+s_{13} \sigma_{r}, \\
e_{t}=2 s_{13} \sigma_{\theta}+s_{33} \sigma_{r},
\end{gathered}
$$

where

$e_{\theta}=$ normal strain in the tangential direction, resulting from stress,

$e_{r}=$ normal strain in the radial direction, resulting from stress, and

$s_{i j}=$ compliance constant, relating strain component $i$ to stress component $j$. Subscripts 1 and

2 represent normal components acting along parallel crystal directions, and subscript 3 represents normal component along perpendicular direction. See ref 9 for further details.

The parallel crystal direction coincides with the tangential direction in the coated particle, while the perpendicular crystal direction coincides with the radial direction in the coated particle. In terms of Young's moduli and Poisson's ratios:

$$
\begin{gathered}
e_{\theta}=\frac{\left(1-\nu_{1}\right) \sigma_{\theta}}{E_{1}}-\frac{\nu_{2} \sigma_{r}}{E_{2}}, \\
e_{r}=\frac{-2 \nu_{3} \sigma_{\theta}}{E_{1}}+\frac{\sigma_{r}}{E_{2}},
\end{gathered}
$$

where

$E_{1}=$ Young's modulus, relating stress in the parallel crystal direction to strain in the same direction,

$E_{2}=$ Young's modulus, relating stress in the perpendicular crystal direction to strain in the same dircction,

$\nu_{1}=$ Poisson's ratio, relating contraction in the parallel layer planes to elongation at right angles but also in the parallel layer planes,

$\nu_{2}=$ Hoisson's ratio, relating contraction in the parallel layer planes to elongation in the perpendicular direction, and

$\nu_{3}=$ Poisson's ratio, relating contraction in the perpendicular crystal direction to elongation in the parallel layer planes.

It may also be noted from hexagonal symmetry that

$$
\frac{\nu_{2}^{\prime}}{E_{2}}=\frac{\nu_{3}^{\prime}}{E_{1}}
$$

If thermal expansion or radiation-induced volume changes occur, the total fractional elongation will be given by the sum of the stress-induced strain, $e$, and expansion terms in the form: 


$$
\begin{aligned}
& \epsilon_{\theta}=e_{\theta}+g_{1}, \\
& \epsilon_{r}=e_{r}+g_{2},
\end{aligned}
$$

with

$$
\begin{aligned}
& \xi_{1}=a_{1}\left(T-T_{c}\right)+\eta_{1}, \\
& g_{2}=a_{2}\left(T-T_{c}\right)+\eta_{2},
\end{aligned}
$$

where

$\epsilon_{\theta}=$ total fractional elongation in the tangential direction,

$\epsilon_{r}=$ total fractional elongation in the radial direction;

$g_{1}=$ fractional linear expansion in the parallel crystal direction,

$\xi_{2}=$ fractional linear expansion in the perpendicular crystal direction,

$a_{1}=$ thermal expansion coefficient in the parallel crystal direction,

$\alpha_{2}=$ thermal expansion coefficient in the perpendicular crystal direction,

$T=$ temperature at a point in a coated particle,

$T_{\mathrm{c}}$ - temperature at which coating was applied to particle,

$\eta_{1}=$ fractional linear expansion in the parallel crystal direction, produced by radiation, and

$\eta_{2}=$ fractional linear expansion in the perpendicular crystal direction, produced by radiation.

The fractional elongation may be related to the radial displacement, $u$, of a point in the coated particle by ${ }^{10}$

$$
\begin{gathered}
\epsilon_{\theta}=\frac{u}{r}, \\
\epsilon_{r}=\frac{d u}{d r} .
\end{gathered}
$$

Combination of Eqs. (4) through (12) and substitution into Eq. (1) will yield a differential equation in a single dependent variable, $u$, which must be solved subject to appropriate boundary condition. Specifically, one must first solve Eqs. (4) and (5) simultaneously for the stresses. The results, expressed in terms of total fractional elongations from Eqs. (7) through (10), are

$$
\begin{aligned}
& \sigma_{\theta}=a_{1} \epsilon_{\theta}+a_{2} \epsilon_{r}+G_{1}, \\
& \sigma_{r}=2 a_{2} c_{\theta}+a_{3} c_{r}+G_{2} .
\end{aligned}
$$

\footnotetext{
${ }^{10} \mathrm{~S}$. Timoshenko and J. N. Goodier, Theory of Elasticity, p 417, McGraw-Hill, New York, 1951.
} 
The a's and G's are related to previously defined parameters by:

$$
\begin{aligned}
& a_{1}=\frac{E_{1}}{1-\nu_{1}-2 \nu_{2} \nu_{3}}, \\
& a_{2}=\frac{E_{1} \nu_{2}}{1-\nu_{1}-2 \nu_{2} \nu_{3}}, \\
& a_{3}=\frac{E_{2}\left(1-\nu_{1}\right)}{1-\nu_{1}-2 \nu_{2} \nu_{3}}, \\
& G_{1}=-\left(a_{1} g_{1}+a_{2} g_{2}\right), \\
& G_{2}=-\left(2 a_{2} g_{1}+a_{3} g_{2}\right) .
\end{aligned}
$$

Under assumption 5 (elastic properties are constant within coating and fuel), the a's will be constant, while the G's may be functions of radial position. When Eqs. (13) and (14) are substituted into Eq. (1) and the displacement introduced through Eqs. (11) and (12), the result is:

$$
r^{2} \frac{d^{2} u}{d r^{2}}+2 r \frac{d u}{d r}-2 \frac{a_{1}-a_{2}}{a_{3}} u=\frac{2 r}{a_{3}}\left(G_{1}-G_{2}\right)-\frac{r^{2}}{a_{3}} \frac{d G_{2}}{d r} .
$$

Boundary conditions for Eq. (20) are not available directly in terms of the displacement, $u$, but are in terms of the radial stress component, $\sigma_{r}$. At the outer surface of the coating, $\sigma_{r}$ must vanish. At the inner surface, $\sigma_{r}$ will be the negative of the gas pressure in the space between fuel and coating if the coating does not remain in contact with the fuel core. If the coating remains in contact with the core, $\sigma_{r}$ at the inner coating boundary must be equal to $\sigma_{r}$ in the fuel at its outer surface to maintain the equilibrium of radial forces. In mathematical terms, those boundary conditions may be expressed as follows:

$$
\sigma_{r}(b-)=0
$$

If the coating and fuel separate,

$$
\sigma_{r}(a+)=-P
$$

and if the coating and fuel remain in contact,

$$
v_{r}\left(a_{t}\right)=v_{r}\left(a_{-}\right),
$$

where

$$
\begin{aligned}
a & =\text { inner radius of coating, } \\
b & =\text { outer radius of coating, } \\
\sigma_{r}(a+) & =\text { limit of } \sigma_{r}(r) \text { as } r \text { approaches a from } r>a,
\end{aligned}
$$




$$
\begin{aligned}
\sigma_{r}\left(a_{-}\right) & =\text {limit of } \sigma_{r}(r) \text { as } r \text { approaches } a \text { from } r<a, \text { and } \\
P & =\text { fission-gas pressure in void space between fuel and coating. }
\end{aligned}
$$

Equation (20) may be recognized as Cauchy's (or Euler's) linear equation, ${ }^{11}$ and solution can be obtained in the form $u=r^{n}$. If this is substituted into Eq. (20) and the left-hand side set equal to zero, one obtains a quadratic equation in $n$,

$$
n^{2}+n+2 \frac{a_{1}-a_{2}}{a_{3}}=0
$$

from which two possible values for $n$ are:

$$
\begin{aligned}
& n_{1}=\frac{-1+\sqrt{1+8\left[\left(a_{1}-a_{2}\right) / a_{3}\right]}}{2}, \\
& n_{2}=\frac{-1-\sqrt{1+8\left[\left(a_{1}-a_{2}\right) / a_{3}\right]}}{2} .
\end{aligned}
$$

The complementary solution, $u_{c}$, to Eq. (20) is then

$$
u_{c}=C_{1} r^{n}+C_{2} r^{n}
$$

where $C_{1}$ and $C_{2}$ are constants of integration to be determined from the boundary conditions. The solution which satisfies the right-hand side of Eq. (20) is found by the method of variation of parameters $^{12}$ as

$$
u(r)=r^{n} \int_{a}^{r} A_{1} r^{-n_{1}} d r-r^{n_{2}} \int_{a}^{r} A_{2} r^{-n_{2}} d r+C_{1} r^{n_{1}}+C_{2} r^{n^{2}}
$$

with .

$$
\begin{aligned}
& A_{1}=\frac{2 G_{1}-\left(1+n_{1}\right) G_{2}}{a_{3}\left(n_{1}-n_{2}\right)}, \\
& A_{2}=\frac{2 G_{1}-\left(1+n_{2}\right) G_{2}}{a_{3}\left(n_{1}-n_{2}\right)} .
\end{aligned}
$$

One can apply Eqs. (11) and (12) to find the fractional elongations:

$$
\begin{gathered}
\epsilon_{\theta}=r^{n^{-1}}\left(C_{1}+\int_{a}^{r} \dot{A}_{1} r^{-n} d r\right)+r^{n^{-1}}\left(C_{2}-\int_{a}^{r} A_{2} r^{-n_{2}} d r\right), \\
\epsilon_{r}=A_{1}-A_{2}+n_{1} r^{n_{1}-1}\left(C_{1}+\int_{a}^{r} A_{1} r^{-n_{1}} d r\right)+n_{2} r^{n^{-1}}\left(C_{2}-\int_{a}^{r} A_{2} r^{-n} d r\right),
\end{gathered}
$$

${ }^{11}$ H. W. Reddick and F. H. Miller, Advanced Mathematics for Engineers, 2d ed., pp 66-68, Wiley, New York, 1947.

${ }^{12}$ H. W. Reddick and F。H.Miller, Advanced Mathematics for Engineers, 2d ed., pp 61-65, Wiley, New York, 1947. 
and the radial stress component is found from Eq. (14) as

$\sigma_{r}=\left(2 a_{2}+a_{3} n_{1}\right) r^{n_{1}-1}\left(C_{1}+\int_{a}^{t} A_{1} r^{-n_{1}} d r\right)+\left(2 a_{2}+a_{3} n_{2}\right) r^{n_{2}-1}\left(C_{2}+\int_{a}^{r} A_{2} r^{-n_{2}} d r\right)$

[In arriving at Eq. (31), note that $a_{3}\left(A_{1}-A_{2}\right)=-G_{2}$. ] It is convenient to find the $C_{1}$ and $C_{2}$ in terms of the normalized displacement of the inner coating boundary, $U_{1 B}$, defined as:

$$
U_{1 B}=\frac{u(a+)}{a} \text {. }
$$

Applying this relation to Eq. (26) and the condition $\sigma_{i}(b-)=0$ to Eq. (31) permits solution for $C_{1}$ and $C_{2}$ as

$$
\begin{aligned}
& C_{1}=\frac{\left[-\left(2 a_{2}+a_{3} n_{1}\right) \bar{A}_{1}+\left(2 a_{2}+a_{3} n_{2}\right) \bar{A}_{2}\right] a^{n_{2}-1}-\left(2 a_{2}+a_{3} n_{2}\right) b^{n_{2}-1} U_{1 B}}{\left(2 a_{2}+a_{3} n_{1}\right) a^{n_{2}} b^{n_{1} 1^{-1}}-\left(2 a_{2}+a_{3} n_{2}\right) a^{n_{1}-1} b^{n_{2}{ }^{-1}}}, \\
& C_{2}=\frac{\left[\left(2 a_{2}+a_{3} n_{1}\right) \vec{A}_{1}-\left(2 a_{2}+a_{3} n_{2}\right) \vec{A}_{2}\right] a^{n_{1}-1}+\left(2 a_{2}+a_{3} n_{1}\right) b^{n_{1}-1} U_{1 B}}{\left(2 a_{2}+a_{3} n_{1}\right) a^{n_{2}-1} b^{n_{1}-1}-\left(2 a_{2}+a_{3} n_{2}\right) a^{n_{1}{ }^{-1} b^{n_{2}-1}}}
\end{aligned}
$$

with

$$
\begin{aligned}
& \bar{A}_{1}-b^{n_{1}-1} \int_{a}^{b} A_{1} r^{-n} d t \\
& \bar{A}_{2}-b^{n} 2^{-1} \int_{a}^{b} A_{2}{ }^{-n} \cdot \text { ir } .
\end{aligned}
$$

It now remains to calculate the normalized displacement at the inner coating surface, $U_{1 B}$. This calculation will depend upon the boundary condition assumed at the surface $r=a$. If the coating separates from the fuel, $\sigma_{r}(a+)=-P$; if separation does not occur, $\sigma_{r}(a+)=\sigma_{r}(a-)$, and $U_{1 B}=U_{1 A}$, the normalized displacement at the outer surface of the fuel. Consider first the case of separation. From Eq. (31)

$$
\left(2 a_{2}+a_{3} n_{1}\right) a^{n_{1}-1} C_{1}+\left(2 a_{2}+a_{3} n_{2}\right) a^{n_{2}-1} C_{2}=-P
$$

Substitution for $C_{1}$ and $C_{2}$ from Eqs. (33) and (34) leads to

$$
U_{1 B}=U_{10}-P \frac{\left(2 a_{2}+a_{3} n_{1}\right)(a / b)^{1-n_{1}}-\left(2 a_{2}+a_{3} n_{2}\right)(a / b)^{1-n_{2}}}{\left(2 a_{2}+a_{3} n_{1}\right)\left(2 a_{2}+a_{3} n_{2}\right)\left[(a / b)^{1-n_{1}}-(a / b)^{1-n_{2}}\right]} .
$$


with

$$
U_{10}=\frac{a_{3}\left(n_{1}-n_{2}\right)\left[\left(2 a_{2}+a_{3} n_{1}\right) \bar{A}_{1}-\left(2 a_{2}+a_{3} n_{2}\right) \bar{A}_{2}\right]}{\left(2 a_{2}+a_{3} n_{1}\right)\left(2 a_{2}+a_{3} n_{2}\right)\left[(a / b)^{1-n_{1}}-(a / b)^{1-n_{2}}\right]} .
$$

It is seen that $U_{10}$ is the no malized displacement of the inner coating surface if the internal gas pressure is zero. Evaluation of $\bar{A}_{1}$ and $\bar{A}_{2}$ requires knowledge of the radial variation of temperature and radiation damage to permit expression of $G_{1}$ and $G_{2}$ as functions of radius. If $G_{1}$ and $G_{2}$ are constant,

$$
\begin{aligned}
& \bar{A}_{1}=\frac{\left[2 G_{1}-\left(1+n_{1}\right) G_{2}\right]\left[1-(a / b)^{1-n_{1}}\right]}{a_{3}\left(n_{1}-n_{2}\right)\left(1-n_{1}\right)}, \\
& \bar{A}_{2}=\frac{\left[2 G_{1}-\left(1+n_{1}\right) G_{2}\right]\left[1-(a / b)^{1-n_{1}}\right]}{a_{3}\left(n_{1}-n_{2}\right)\left(1-n_{2}\right)},
\end{aligned}
$$

and these may be substituted in Eq. (39)

If separation does not occur between coating and fuel, one must determine the radial stress in the fuel core in order to apply boundary condition (23). Within the fuel it is assumed that isotropic conditions prevail; hence there is only one modulus of elasticity, $E_{A}$, one Poisson's ratio, $\nu_{A}$, and one linear expansion factor, $\varepsilon_{A}$. Equation (20) becomes

$$
t^{2} \frac{d^{2} u}{d r^{2}}+2 r \frac{d u}{d r}-2 u=r^{2}\left(\frac{1+\nu_{A}}{1-\nu_{A}}\right) \frac{d g_{A}}{d r} .
$$

Solution may be accomplished as for Eq. (20), although in this case the left-hand side may be made exact by dividing through by $t^{2}$ and the equation solved by integrating twice. By either method, the solution is

$$
u(r)=\left(\frac{1+\nu_{A}}{1-\nu_{A}}\right) \frac{1}{r^{2}} \int_{0}^{r} g_{A} r^{2} d r+C_{3} r
$$

where $C_{3}$ is a constant of integration, to be determined from boundary cunditions.

A second integration constant can be shown to vanish inside the fuel core since the displacement must remain finite at the center of the sphere $(r=0)$. The single remaining constant, $C_{3}$, can be expressed in terms of the normalized displacement at the outer fuel boundary, $U_{1 A}$, as:

$$
C_{3}=U_{1 A}-\left(\frac{1+\nu_{A}}{1-\nu_{A}}\right) \frac{\bar{g}_{A}}{3}
$$


with

$$
\bar{g}_{A}=\frac{3}{a_{f}^{3}} \int_{0}^{a}{ }_{t} \xi_{A} r^{2} d r
$$

where $a_{f}$ is outer radius of fuel core.

From Eqs. (11) and (12)

$$
\begin{aligned}
& \epsilon_{\theta}=U_{1 A}-\frac{1+\nu_{A}}{1-\nu_{A}}\left(\frac{\bar{\Xi}_{A}}{3}-\frac{1}{r^{3}} \int_{0}^{r} g_{A} r^{2} d r\right), \\
& \epsilon_{r}=U_{1 A}+\frac{1+\nu_{A}}{1-\nu_{A}}\left(g_{A}-\frac{\xi_{A}}{3}-\frac{2}{r^{2}} \int_{0}^{i} g_{A} r^{2} d r\right) .
\end{aligned}
$$

For an isotropic material Eq. (14) reduces to

$$
\sigma_{r}=\frac{E}{1-\nu_{A}-2 \nu_{A}^{2}}\left[2 \nu_{A} \epsilon_{\theta}+\left(1-\nu_{A}^{\prime}\right) c_{r}-\left(1+\nu_{A}\right) g_{A}\right] \text {. }
$$

From Eqs. (46), (47), and (48)

$$
\sigma_{\mathrm{r}}=\frac{E_{A}}{1-2 \nu_{A}}\left\{U_{1 A}-\left(\frac{1+\nu_{A}}{1-\nu_{A}}\right) \frac{\bar{g}_{A}}{3}-\left(\frac{1-2 \nu_{A}}{1-\nu_{A}}\right) \frac{2}{r^{3}} \int_{0}^{r} \dot{g}_{A} r^{2} d r\right\} .
$$

If contact is maintained between the fuel core and the coating, $U_{1 A}=U_{1 B}$ and $a_{f}=a$; hence boundary condition (22) may be used with Eqs. (31), (33). (34), and (49) to find $J_{1 B^{\circ}}$. The result is given in the following form:

$$
U_{1 B}=\frac{\bar{\varepsilon}_{A}+\gamma U_{10}}{1+\gamma}
$$

with

$$
\gamma=\frac{\left[\left(1-2 \nu_{A}\right) / E_{A}\right]\left(2 a_{2}+a_{3} n_{1}\right)\left(2 a_{2}+a_{3} n_{2}\right)\left[1-(a / b)^{n_{1}-n_{2}}\right]}{\left(2 a_{2}+a_{3} n_{2}\right)(a / b)^{n_{1}-n_{2}}-\left(2 a_{2}+a_{3} n_{1}\right)},
$$

and $U_{10}$ given by Eq. (39). Note that if the temperature and radiation effects in the fuel are independent of radial position, $\xi_{A}$ will be constant and

$$
\bar{g}_{A}=g_{A} .
$$

In analyzing the possibility of coating breakage, one is primarily concerned with the tangential stress component (or "hoop" stress) in the coating, $\sigma_{\theta}$, and the strain produced by the stress, 
$e_{\theta}$. Note that when considering breakage, the strain, $e$, and not the total fractional elongation, $\epsilon$, should be of importance since it is possible to have an unconstrained heated sample which is in a state of zero stress but nonzero elongation. The equations of interest are:

$$
\begin{array}{r}
\sigma_{\theta}=\left(a_{1}+a_{2} n_{1}\right) r^{n_{1}^{\prime}-1}\left(C_{1}+\int_{a}^{r} A_{1} r^{-n_{1}} d r\right)+\left(a_{1}+a_{2} n_{2}\right) r^{n_{2}-1}\left(C_{2}-\int_{a}^{r} A_{2} r^{-n_{2}} d r\right) \\
+\frac{2 a_{2}^{2}-a_{1} a_{3}}{a_{3}} g_{1}, \\
e_{\theta}=r^{n_{1}-1}\left(C_{1}+\int_{a}^{r} A_{1} r^{-n_{1}} d r\right)+r^{n_{2}-1}\left(C_{2}-\int_{a}^{r} A_{2} r^{-n_{2}} d r\right)-g_{1},
\end{array}
$$

with $C_{1}$ and $C_{2}$ given in terms of $U_{1 B}$ by Eqs. (33) and (34) and $U_{1 B}$ found from Eqs. (38), (39), $(50)$, and (51). For uniform temperature and radiation effects,

$$
r_{r}^{n_{1}-1} \int_{a}^{r} A_{1} r^{-n_{1}} d r=\frac{A_{1}}{1-n_{1}}\left[1-\left(\frac{a}{r}\right)^{1-n_{1}}\right],
$$

and $\bar{A}_{1}$ and $\bar{A}_{2}$, appearing in $C_{1}$ and $C_{2}$, are given by Eqs. (40) and (41).

\section{Isotropic Stress-Strain Relations with Ani sotropic Expansion}

The preceding results can be considerably simplified if the coating is assumed to exhibit isotropic elastic behavior while retaining the anisotropic dimensional changes from thermal expansion and radiation. The coating elastic behavior can be described by a single Young's modulus, $E_{B}=$ $E_{1}=E_{2}$, and a single Poisson's ratio, $\nu_{B}=\nu_{1}=\nu_{2}=\nu_{3}$. The subscript $B$ is retained for the shell to distinguish its properties from those of the core. Then

$$
\begin{gathered}
a_{1}=\frac{E_{B}}{\left(1+\nu_{B}\right)\left(1-2 \nu_{B}\right)^{\prime}} \\
a_{2}=\frac{E_{B} \nu_{B}}{\left(1+\nu_{B}\right)\left(1-2 \nu_{B}\right)}, \\
a_{3}=a_{1}-a_{2}, \\
G_{1}=\frac{-E_{B}\left(g_{1}+\nu_{B} g_{2}\right)}{\left(1+\nu_{B}\right)\left(1-2 \nu_{B}\right)}, \\
G_{2}=\frac{-E_{B}\left[2 \nu_{B} g_{1}+\left(1-\nu_{B}\right) g_{2}\right]}{\left(1+\nu_{B}\right)\left(1-2 \nu_{B}\right)} .
\end{gathered}
$$


From Eqs. (17a) and (24), it is seen that $n_{1}=1, n_{2}=-2$, and hence

$$
\begin{aligned}
& A_{1}=-\frac{2}{3}\left(g_{1}-g_{2}\right) \frac{1-2 \nu_{B}}{1-\nu_{B}}, \\
& A_{2}=-\left(\frac{2 g_{1}+g_{2}}{3}\right) \frac{1+\nu_{B}}{1-\nu_{B}} .
\end{aligned}
$$

The reduction for this special case is straightforward, and results are given as follows:

$$
\begin{aligned}
& \sigma_{\theta}=\frac{E_{B}}{1-2 \nu_{B}} \quad\left(C_{1}+\int_{a}^{r} \frac{A_{1}}{r} d r\right)+\frac{E_{B}}{1+\nu_{B}} \quad\left(\frac{C_{2}}{t^{3}}-\frac{1}{r^{3}} \int_{a}^{r} A_{2} r^{2} d r\right)-\frac{E_{B} g_{1}}{1-\nu_{B}}, \\
& e_{\theta}=C_{1}+\int_{a}^{t} \frac{A_{1}}{r} d r+\frac{C_{2}}{r^{3}}-\frac{1}{r^{3}} \int_{a}^{r} A_{2} \mathrm{r}^{2} d r-\xi_{1}, \\
& C_{1}=-\frac{\bar{A}_{1}+2 \bar{A}_{2}\left[\left(1-2 \nu_{B}\right) /\left(1+\nu_{B}\right)\right]-2(a / b)^{3}\left[\left(1-2 \nu_{B}\right) /\left(1+\nu_{B}\right)\right] U_{1 B}}{1+2(a / b)^{3}\left[\left(1-2 v_{B}\right) /\left(1+\nu_{B}\right)\right]} . \\
& C_{2}=a^{3} \frac{\vec{A}_{1}+2 \bar{A}_{2}\left[\left(1-2 \nu_{B}\right) /\left(1+\nu_{B}\right)\right]+U_{1 B}}{1+2(a / b)^{3}\left[\left(1-2 \nu_{B}\right) /\left(1+\nu_{B}\right)\right]} \\
& \bar{A}_{1}=--_{3}^{2}\left(\begin{array}{c}
1-2 \nu_{B} \\
1-\nu_{B}
\end{array}\right) \int_{a}^{b} g_{1}-g_{2} d t
\end{aligned}
$$

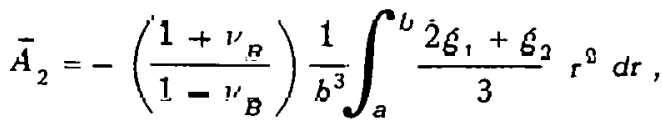

$$
\begin{aligned}
& U_{10}=\frac{3}{b^{3}-a^{3}} \int_{a}^{b} \frac{2 g_{1}+g_{2}}{3} r^{2} d r+\frac{\int_{a}^{b}\left[\left(g_{1}-g_{2}\right) / r\right] d r}{1-(a / b)^{3}} .
\end{aligned}
$$

If separation of the coating from the fuel occurs,

$$
U_{1 B}-U_{10}+P\left(\frac{1+\nu_{B}}{2 E_{B}}\right) \frac{1+2(a / b)^{3}\left[\left(1-2 \nu_{B}\right) /\left(1+\nu_{B}\right)\right]}{1-(a / b)^{3}},
$$

and if fuel and coating remain in contact,

$$
U_{1 B}=\frac{\bar{\xi}_{A}+\gamma U_{10}}{1+\gamma}
$$

with

$$
\gamma=\frac{2\left(E_{B} / E_{A}\right)\left[\left(1-2 \nu_{A}\right) /\left(1+\nu_{B}\right)\right]\left[1-(a / b)^{3}\right]}{1+2(a / b)^{3}\left[\left(1-2 \nu_{B}\right) /\left(1+\nu_{B}\right)\right]} .
$$


Calculations with the above equations require knowledge of the variation of temperature and radiation damage with position, that is, $g_{A}(r), g_{1}(r)$, and $g_{2}(r)$. If these quantities are assumed uniform throughout fuel and coating, further simplifications result. These are presented below with certain terms grouped to facilitate calculations.

$$
\begin{gathered}
\sigma_{\theta}=\frac{E_{B}}{1-\nu_{B}}\left[\left(U_{1 B}-\frac{2 g_{1}+g_{2}}{3}\right) F_{3}-\frac{2}{3}\left(g_{1}-g_{2}\right) F_{4}-\frac{1}{3}\left(g_{1}-g_{2}\right)\right], \\
e_{\theta}=\left(U_{1 B}-\frac{2 g_{1}+g_{2}}{3}\right) F_{1}-\frac{2}{3}\left(g_{1}-g_{2}\right) F_{2}-\frac{1}{3}\left(g_{1}-g_{2}\right),
\end{gathered}
$$

with

$$
\begin{gathered}
F_{1}=\frac{(a / r)^{3}+2(a / b)^{3}\left[\left(1-2 \nu_{B}\right) /\left(1+\nu_{B}\right)\right]}{1+2(a / b)^{3}\left[\left(1-2 \nu_{B}\right) /\left(1+\nu_{B}\right)\right]}, \\
F_{2}=\frac{1-2 \nu_{B}}{1-\nu_{B}}\left(\ln \frac{r}{a}-\left\{\frac{1-(a / r)^{3}}{1+2(a / b)^{3}\left[\left(1-2 \nu_{B}\right) /\left(1+\nu_{B}\right)\right]}\right\} \ln \frac{b}{a}\right), \\
F_{3}=\left(\frac{1-\nu_{B}}{1+\nu_{B}}\right) \frac{(a / r)^{3}+2(a / b)^{3}}{1+2(a / b)^{3}\left[\left(1-2 \nu_{B}\right) /\left(1+\nu_{B}\right)\right]}, \\
F_{4}=\ln \frac{r}{a}-\left\{\frac{1-(a / r)^{3}\left[\left(1-2 \nu_{B}\right) /\left(1+\nu_{B}\right)\right]}{1+2(a / b)^{3}\left[\left(1-2 \nu_{B}\right) /\left(1+\nu_{B}\right)\right]}\right\} \ln \frac{b}{a} .
\end{gathered}
$$

The terms $y$ and $U_{1 B}$ are obtained as before from Eqs. (51a) and (38a) or (50) with

$$
U_{10}=\frac{2 g_{1}+g_{2}}{3}+\frac{\left(g_{1}-g_{2}\right) \ln (b / a)}{1-(a / b)^{3}}
$$

There equations are used in the calculation in the body of the report to develop radial profiles of $e_{\theta}$ and a normalized stress, $\sigma_{\theta}\left(1-\nu_{B}\right) / E_{B}$, vs $r$.

\section{Completely Isotropic Behavior}

The relations developed above can be simplified even more if coating expansion behavior as well as the elastic properties are isotropic. In such a case, $g_{1}=g_{2}=g_{B}, A_{1}=\bar{A}_{1}=0$; and the resulting equations are:

$$
\begin{aligned}
& \sigma_{\theta}=\frac{E_{B}}{1-\nu_{B}}\left(F_{3} U_{1 B}+F_{6} \bar{g}_{B}+\frac{1}{r^{3}} \int_{a}^{r} g_{B} r^{2} d r-g_{B}\right), \\
& e_{\theta}=F_{1} U_{1 B}+F_{5} \bar{g}_{B}+\frac{1}{r^{3}}\left(\frac{1+\nu_{B}}{1-\nu_{B}}\right) \int_{a}^{r} g_{B} r^{2} d r-g_{B},
\end{aligned}
$$


with

$$
\begin{gathered}
F_{5}=\frac{2}{3}\left(\frac{1-2 \nu_{B}}{1-\nu_{B}}\right) \frac{\left[1-(a / b)^{3}\right]\left[1-(a / r)^{3}\right]}{1+2(a / b)^{3}\left[\left(1-2 \nu_{B}\right) /\left(1+\nu_{B}\right)\right]}, \\
F_{6}=\frac{2}{3}\left[1-\left(\frac{a}{b}\right)^{3}\right] \frac{1-(a / r)^{3}\left[\left(1-2 \nu_{B}\right) /\left(1+\nu_{B}\right)\right]}{1+2(a / b)^{3}\left[\left(1-2 \nu_{B}\right) /\left(1+\nu_{B}\right)\right]}, \\
\bar{g}_{B}=\frac{3}{b^{3}-a^{3}} \int_{a}^{b} g_{B} r^{2} d r, \\
U_{10}=g_{B},
\end{gathered}
$$

and $\gamma$ and $U_{1 B}$ are as given in Eqs. (51a) and (38a) or (50).

If radially independent expansion effects are assumed, the relations for stress and strain reduce even further to

$$
\begin{gathered}
\sigma_{\theta}=\frac{E_{B}}{1-\nu_{B}}\left(U_{1 B}-g_{B}\right) F_{3}, \\
e_{\theta}=\left(U_{1 B}-g_{B}\right) F_{1},
\end{gathered}
$$

with $F_{1}$ and $F_{3}$ given by Eqs. (56) and (58). It is uprth noting that for $V_{1 B}$ ' $\delta_{B}$, allu uu rudiul $g$ variations, $\sigma_{\theta}$ and $\epsilon_{\theta}$ will both attain their maximum values at the inner coating surface, $r=a$, since $F_{1}$ and $F_{3}$ are always positive and attain maximum values for $r-a$. Thic conclusion dues uul luvld, however, for the anisotropic cases considered. 


\section{Appendix B}

\section{PRESSURE AND DISPLACEMENT CALCULATIONS}

The determination of fission-gas pressure in cases where a gap exists between core and coating requires a trial-and-error calculation. This results from the strong dependence of the pressure on gap volume which, in turn, depends to some extent on the pressure itself.

The van der Waals equation of state is well suited for calculation of gas pressure since expected gap conditions (high temperature and high pressure) are in its range of best applicability.

$$
P=\frac{R T_{G}}{\left(V_{G} / n_{G}\right)-\hat{b}}-\frac{\hat{a}}{\left(V_{G} / n_{G}\right)^{2}},
$$

where

$P=$ gas pressure in gap,

$R=$ gas constant,

$T_{g}=$ absolute temperature in gas,

$V_{G}=$ total volume occupied by fission gas,

$n_{G}=$ moles of fission gas, and

$\hat{a}, \hat{b}=$ van der Waals constants (average values for fission-gas mixture expected).

The moles of fission gas can be obtained in terms of the fuel properties and the percent burnup of the fissile and fertile atoms as

$$
n_{G}=V_{f} \rho_{f} \frac{\mathrm{Bu}}{100} \gamma_{\mathrm{G}} f\left(\frac{X_{\mathrm{U}}}{M_{\mathrm{U}}}+\frac{X_{\mathrm{Th}}}{M_{\mathrm{Th}}}\right),
$$

where

$V_{f}=$ volume of fuel,

$\rho_{f}=$ density of fuel material,

$\mathrm{Bu}=$ percentage burnup of fissile and fertile atoms originally present,

$\gamma_{G}=$ total yield of gaseous fission products (gas atoms produced per fission),

$f=$ fraction of fission gas released from fuel (atoms released per atom formed),

$X_{\mathrm{U}}, X_{\mathrm{Th}}=$ mass fractions of uranium and thorium, respectively, in fuel, and

$M_{\mathrm{U}}, M_{\mathrm{Th}}=$ atomic weights of uranium and thorium, respectively.

The volume initially occupied by the gas is calculated under the assumption that fuel and pyrolytic carbon coating are nonporous and that a gap filled with porous material may exist between fuel and coating. Thus, initially

$$
V_{G}=\frac{4}{3} \pi\left[\left(a_{f}+y\right)^{3}-a_{f}^{3}\right] d_{d},
$$

with

$$
a-a_{f}+y,
$$


where

$a_{f}=$ initial radius of fuel core,

$a=$ initial inner radius of pyrolytic carbon coating,

$y=$ initial gap width between coating and fuel, and

$\phi=$ fractional open porosity of gap.

At operating conditions, volume changes in fuel and coating may alter both the size and porosity of the gap and thence the gas volume. A new gas volume can be computed under the assumption that any solid material in the gap is incompressible and that all gap volume changes are accommodated by a change in porosity. Should gap shrinkage eliminate the gas volume entirely, the problem is treated as if no fission gas or gap were present and coating and fuel remained in contact.

An etfective thickness tor the solid material in the gap can be computed by considering the gap as containing a fictitious zero-porosity solid layer and free gas space in series.

$$
t=\left(\frac{3 V_{s}}{1 \pi}+a_{f}^{3}\right)^{1 / 3}-a_{f},
$$

where

$t=$ effective thickness of solid material in gap,

$V_{s}=$ effective volume of solid material in gap.

The effective solid volume is

$$
v_{s}=\frac{4}{3} \pi\left[\left(a_{f}+y^{3}\right)^{3}-a_{f}^{3}\right](1-\phi) .
$$

Equations (67) and (68) may be combined to yield

$$
\frac{t}{a_{f}}=\left[\left(1+\frac{y}{a_{f}}\right)^{3}(1-\phi)+\phi\right]^{1, j}-1 \text {. }
$$

Under operating conditions, the fuel core will undergo a fractional outward displacement, $U_{1 A}$ (including the effective gap solid thickness), given by

$$
U_{1, A}=g_{A}-\frac{P}{E_{A}\left(1-2 \nu_{A}\right)}+\frac{t}{a_{f}}
$$

the fractional displacement of the inner coating surface, $U_{1 B}$, assuming isotropic elastic behavior in the coating, is given by Eq. (38a), Appendix A.

The new gas volume is then

$$
V_{G}=\frac{4}{3} \pi\left[a^{3}\left(1+U_{1 B}\right)^{3}-a_{f}^{3}\left(1+U_{1 A}\right)^{3}\right]
$$


It is the dependence of $U_{1 A}$ and $U_{1 B}$ on pressure [Eqs. (38a) and (70)] and the dependence, in turn, of pressure on gas volume [Eq. (63)] which forces a trial-and-error calculation for pressure. The recommended procedure is a direct iteration as follows:

1. calculate $n_{G}$ and $t$ directly from Eq. (64) based on assumed gap and fuel properties, burnup, and release;

2. take trial values of $U_{1 A}=g_{A}$ and $U_{1 B}=U_{10}$;

3. calculate trial $V_{G}$ from Eq. (71);

4. calculate pressure from Eq. (63);

5. calculate new $U_{1 A}$ from Eq. (70) and $U_{1 B}$ from Eq. (38b); and

6. if $U_{1 B}$ does not agree with trial value within acceptable tolerance, repeat steps 3,4 , and 5 , using new values of $U_{1 A}$ and $U_{1 B}$, until satisfactory agreement on $U_{1 D}$ is obtained.

In general, $U_{1 A}$ and $U_{1 B}$ are not too sensitive to pressure, and $U_{1_{B}}$ changes less than $1 \%$ after one or two trials. 


\section{Appendix C \\ TEMPERATURE-DROP CALCULATION FOR COATED PARTICLE UNDER OPERATING CONDITIONS}

An estimate of the temperature drop from the center of the fuel core to the outer coating surface of a spherical coated particle may be obtained from a simple heat-transfer calculation, based on the assumptions of uniform heat generation in the core, no heat generation in gap or coating, and constant thermal conductivities in the core, gap, and coating regions.

The equations required may be obtained with slight modification from those given by Etherington. ${ }^{13}$ The temperature drop across the fuel is given by

$$
T_{\mathrm{o}}-T_{f}=\frac{W}{8 \pi a_{f} k_{f}},
$$

across the gap between fuel and coating by

$$
T_{f}-T_{a}=\frac{W}{4 \pi k_{g}}\left(\frac{a-a_{f}}{a a_{f}}\right)
$$

and across the coating itself by

$$
T_{a} \quad T_{\dot{b}}=\underset{4 \pi k_{s}}{W}\left(\frac{b-a}{a b}\right),
$$

where

$T_{\mathrm{o}}=$ temperature at center of fuel core,

$T_{f}=$ temperature at outer fucl surface,

$T_{a}=$ temperature at inner coating surface,

$T_{h}=$ temperature at outer coating surface,

$W=$ power generation rate in fuel core, energy per unit time,

$k_{f}=$ thermal conductivity of fuel core,

$k_{g}=$ effective thermal conductivity of gap material, and

$k_{\mathrm{s}}=$ thermal conductivity of pyrolytic carbon coating across layer planes (in the c direction). Equations (72) through (74) may be added together to provide the total center-to-surface temperature drop for the coated particlc.

Calculations were made with the above equations for the case of a $200-\mu$-diam fuel core consisting of a thorium-uranium carbide with a 7:1 thorium-uranium atom ratio and a carbon-to-heavymetal atom ratio of 1.85:1. A fuel density of $11.7 \mathrm{~g} / \mathrm{cm}^{3}$, uranium enrichment of $93 \mathrm{wt} \% \mathrm{U}^{235}$, and

\footnotetext{
${ }^{13}$ H. Etherington (ed.), Nuclear Engineering Handbook, pp 1-57, McGraw-Hill, New York, 1958.
} 
fission cross section of 548 barns for $U^{235}$ were assumed. Burnups of thorium and $U^{238}$ were neglected. For these conditions the relation between power generation, $W$, and reactor flux, $\phi^{*}$, was found as

$$
W=2.37 \times 10^{-16} \phi^{*} w
$$

where $\phi^{*}=$ thermal neutron flux at particle, neutrons $\mathrm{cm}^{-2} \mathrm{sec}^{-1}$. Additional data used for the calculation were:

$$
\begin{aligned}
k_{f} & \left.=0.266 \mathrm{w} \mathrm{cm}^{-1} \mathrm{sec}^{-1} \quad \text { (ref } 14\right), \\
k_{\mathrm{G}} & =1.94 \times 10^{-4} \mathrm{w} \mathrm{cm}^{-1} \mathrm{sec}^{-1} \quad \text { (assumed pure xenon), } \\
k_{\mathrm{s}} & =0.012 \mathrm{w} \mathrm{cm}^{-1} \mathrm{sec}^{-1} \quad \text { (ref 15), } \\
a & =105 \mu, \\
b & =200 \mu \\
y & =5 \mu .
\end{aligned}
$$

Using these numbers in Eqs. (72) through (74), one obtains

$$
T_{\mathrm{o}}-T_{b}=5.39 \times 10^{-13} \psi^{*} \mathrm{deg} \mathrm{C} .
$$

For most power reactor applications, therefore, the temperature drop would probably be below $20^{\circ} \mathrm{C}$ and should still be well below $100^{\circ} \mathrm{C}$ even for high-flux test reactors. These numbers are quite conservative for the fuel assumed, since it is doubtful that the gap conductivity would ever be as low as that of a $5-\mu$ thickness of xenon. However, use of a different fuel material for the core would increase them considerably - up to a factor of 8 for enriched UC ${ }_{2}$.

The temperature drop across the coating itself is found from Eq. (74) as

$$
T_{a}-T_{b}=7.1 \times 10^{-14} \phi^{*} \mathrm{deg} \mathrm{C} .
$$

The difference between overall and coating temperature drops lies primarily in the temperature drop across the assumed gáp; that acrošs the fuel core is almost negliglble.

\footnotetext{
${ }^{14}$ R. W. Endebrock (ed.), Properties of Fuels for High-Temperature Reactor Concepts, BMI-1 598, p 41 (Nove mber 1962).

15."Pyrolytic Graphite Preliminary Engineering Data," General Electric Co., Detroit, Mich. (no date).
} 
Appendix D

\section{COMPUTER PROGRAM "STRETCH" FOR CALCULATING AND PLOTTING STRESS AND STRAIN PROFILES}

The calculation program employed in the present work was written in FORTRAN language for execution on the CDC 1604-A computer, and plotting of results on the Calcomp plotter. Program statements are compatible with the IBM 709-7090 processors; compatibility with the IBM 1620-2 processor can be obtained by omitting the plotting segment of the program, breaking up the output format statement to reduce the number of continuation cards, and changing the "read input tape" and "write output tape" statements to "read" and "punch" statements, respectively.

Calculations are performed under the assumptions discussed at the beginning of Appendix A. In addition, it is assumed that temperature and radiation damage are independent of radial position in the coating and that the Young's modulus and Poisson's ratio in the coating are independent of orientation. The significance of these assumptions is discussed in the body of the report.

The program is designed to calculate radial profiles of tangential strain, tangential stress, and normalized tangential stress for a given coated particle, at given conditions of temperature and radiation history. Separate curves of strain and normalized stress, as functions of radial position, can be drawn automatically. If desired, several strain or normalized stress curves can be plotted on the same graph to show the effect of various conditions on the profiles in a given particle.

The input information required for the calculations is punched on standard data cards as shown iii Talje D-1.

Cards 6 and 7 must be repeated for each curve to be plotted on the same graph. Cards 2 through 5 must be repeated for each separate pair of stress and strain graphs. Card 1 is supplied only once. As an example, the order in which data cards would be supplied for a calculation in which four separate pairs of stress and strain plots were to be produced with three curves on each plot would be:

$1,2,3,4,5,6,7,6,7,6,7,2,3,4,5,6,7,6,7,6,7,2,3,4,5,6,7,6,7,6,7,2,3,4,5$, $6,7,6,7,6,7-(41$ cards in all).

This was the input card order required for the illustrative calculations employed in the present report.

The total number of conditions which can be considered in a single run (number of pairs of stress and strain plots times number of curves per plot) is presently limited to 20 . However, this limitation can be removed by increasing the allowable range of subscripts in the "dimension" statement at the beginning of the program.

A listing of the FORTRAN program follows. Control statements required by the monitor system for the particular machine employed are omitted. 
Table D-1. Input Information for Program STRETCH

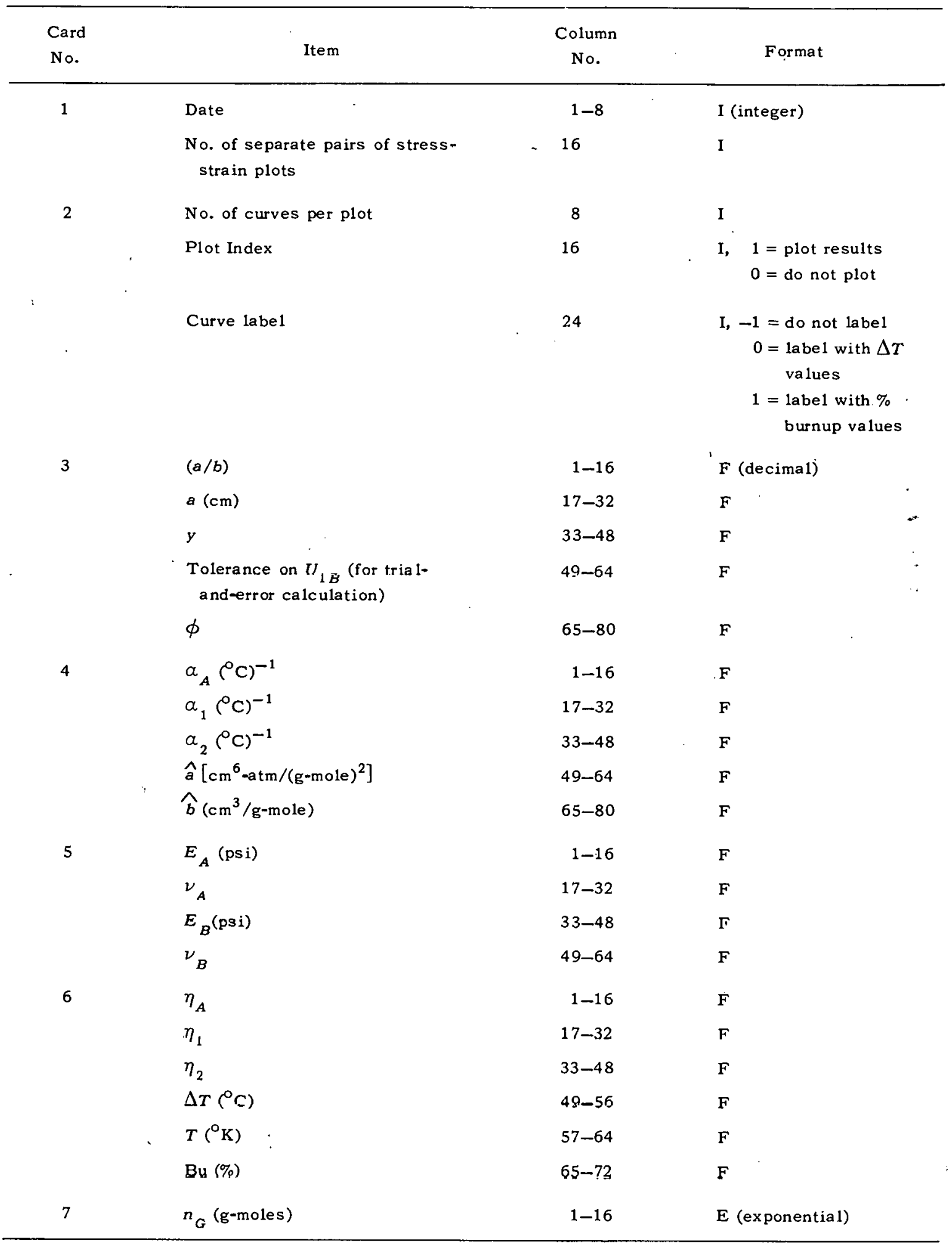




\section{PROGRAM STRETCH}

C

DIMENSION PL.TARRAY $(2.500), Z(21), \operatorname{ET}(20,21), \operatorname{SIGTN}(20,21), \operatorname{SIGT}(2.0,21)$, 1LDELT(20), BURN( 20)

READ INPUT TAPE 10,200, NDATE,NTT

2.00 FORMAT ( 2.18)

$N T=1$

2.01. READ INPUT TAPE 10,2,NC, LP, LABC

2. FORMAT (318)

READ INPUT TAPE 10,3, AB, RADIUS, GAP, TOL. PH I

READ INPUT TAPE 10,3 , AL.FA, ALF1, ALF2, VA, VB

3 FORMAT( $5 F 16.8)$

READ INPUT TAPE $10,4, E A, P O \mid A, E B, P O I B$

4 FORMAT ( $4 F 16.8)$

$\mathrm{N}=1$

1 READ INPUT TAPE $10,2.02$, ETAA, ETA1, ETA2, DELT, TABS, BURN(N)

2.02 FORMAT( $3 F 16.8,3 F 8.1)$

READ INPUT TAPE 10,203,GASMOI.

2.03 FORMAT(E16.8)

$\operatorname{LDELT}(N)=D E L . T$

C

c. CAI CIII ATF PROFIIFS

C

C

C CALCULATE UI GF1 GF2. GF3

c

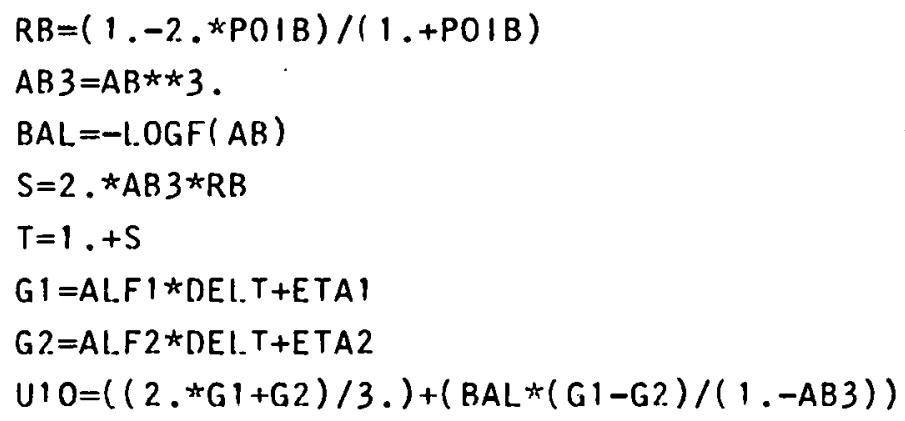


THICK $=((1 .-P H I) *($ RADIUS $/($ RADIUS-GAP $)) * * 3 .+P H I) * * 0.33333333-1$.

$G A=A L F A * D E I . T+E T A A+T H I C K$

U1AT $=G A$

U1 BT $=U 10$

$14 V G=4.1888 *((\operatorname{RADIUS} *(1 .+U 1 R T)) * * 3 .-(($ RADIUS-GAP $) *(1 .+(11 A T)) * * 3)$.

IF(VG) $11,11,10$

10 IF(GASMOL.) 12,12,13

$12 U 1 A=U 1 A T$

$U 1 B=U 1 B T$

$P=.0$

GO TO 2.0

13 CONTINUE

C

$P=14.696 *(82.057 * T A B S /((V G / G A S M O L)-V B)-V A /((V G / G A S M O L) * * 2)$.

$U 1 A C=G A-P *(1,-2 . * P O \mid A) / E A$

$U 1 B C=(110+(P *(1 .+P O \mid B) * T) /(2 . \star E B *(1 .-A B 3))$

$E R R=A B S F(U 1 B C-U 1 B T)$

IF (ERR-TOL.) $15,15,16$

16 UIAT $=U 1 A C$

$U I B T=U 1 B C$

GO TO 14

15. U1A=U1AC

$U 1 B=U 1 B C$

GO TO 20

$11 \mathrm{GAMMA}=2 . * E B *(1 .-2 . * P O \mid A) *(1 .-A B 3) /(E A * T *(1 .+P O \mid B))$

$U 1 B=(G A+G A M M A * U 10) /(1 .+G A M M A)$

$U 1 A=U 1 B$

$P=E A *(G A-U \mid A) /(1 .-2 . * P O \mid A)$

$20 G F 1=(11 B-(2, * G 1+G 2) / 3$.

$G F 3=(G 1-G 2) / 3$.

$\mathrm{GF} 2=\mathrm{GF} 3+\mathrm{GF} 3$

C 
C

C$$
Q=1 . / A B-1 \text {. }
$$$$
R F=0.0
$$$$
\text { DO } 30 \quad I=1,11
$$$$
Z(1)=R F
$$$$
A R=1 . /(1 .+Q * R F)
$$$$
A R 3=A R * * 3 \text {. }
$$$$
R A L=-\operatorname{LOGF}(A R)
$$$$
\text { RADF } 1=(A R 3+S) / T
$$$$
\text { RADF } 2=(1 .-2 . * P O \mid B) *(R A L-B A L *(1 .-A R 3) / T) /(1 .-P O \mid B)
$$$$
\text { RADF } 3=(1 .-P O \mid B) *(A R 3+2 . * A B 3) /((1 .+P O \mid B) * T)
$$$$
\text { RADF 4=RAL. }-B A L *(1 .-A R 3 * R B) / T
$$$$
E T(N, 1)=(G F 1 * R A D F 1-G F 2 \star R A D F 2-G F 3)
$$$$
\operatorname{SIGTN}(N, 1)=G F 1 * R A D F 3-G F 2 * R A D F 4-G F 3
$$$$
\operatorname{SIGT}(N, 1)=E B * \operatorname{SIGTN}(N, 1) /(1 .-P O \mid B)
$$$$
30 R F=R F+0.1
$$

C

WRITE OUTPUT TAPE $9,5, \mathrm{NT}, \mathrm{N}$, NDATE

5 FORMAT( $1 \mathrm{H} 1,5 \mathrm{X}, 29 \mathrm{HINPUT}$ INFORMATION CASE NUMBER, $13,1 \mathrm{H}-, 12,110,1 / 1 /$ ) WRITEOUTPUTTAPE 9,6, EA , EB, POIA, POIB, AB, ALFA, ALFI, ALF2, DEL.T, TABS, IETAA, ETA1, ETA2, BURN(N), RADIUS, GAP, PHI, GASMOL, VA, VB

6 FORMAT(6X, 4HEA $=$. E12.4.4H PSI.7X, 4HEB $=, E 12.4,4 \mathrm{H}$ PSI,7X, 6HPOIA =, 1F5.3,7X, 6HPOIB $=, F 5.3,7 X, 14 \mathrm{HA}$ TO B RATIO $=, F 7.5 / / 16 \mathrm{X}, 9 \mathrm{HAL}$. PHA A $=$, $2 \mathrm{E} 12.4,2 \mathrm{H} / \mathrm{C},{ }_{1} \mathrm{X}, 9 \mathrm{HAI} . \mathrm{PHA} 1=, \mathrm{E} 12.4,2 \mathrm{H} / \mathrm{C}, 4 \mathrm{X}, 9 \mathrm{HALPHA} 2=, \mathrm{E} 12.4,2 \mathrm{H} / \mathrm{C}, 4 \mathrm{X}$, 39HDEL.TA $T=, F 6.0,1 \mathrm{HC}, 4 \mathrm{X}, 3 \mathrm{HT}=, \mathrm{F5} .0,1 \mathrm{HK} / / / 6 \mathrm{X}, 7 \mathrm{HETA} A=, \mathrm{E} 12.4,3 \mathrm{X}$, 47HETA $1=, E 12.4,3 X, 7$ HETA $2=, E 12.4,3 X, 8$ HBURNUP $=, F 4.1,9 H$ PER CENT $5 / / / 6 X, 2.2 H C O A T I N G$ INNER RADIUS $=, E 12.4,3 \mathrm{H} \mathrm{CM}, 3 X, 13 \mathrm{HINITIAL}$ GAP $=$, $6 E 12.4,3 \mathrm{H} \mathrm{CM}, 3 \mathrm{X}, 14 \mathrm{HGAP}$ POROSITY $=, F 5.3,1 / / 6 \mathrm{X}, 2.1 \mathrm{HMOLS}$ OF FISSION GAS $7=$, E12.4, 10X,18HVAN DER WAALS $A=$, E12.4,15H ATM CM6/MOL2, 3HB =, $8 \mathrm{E} 12.4,8 \mathrm{H} \mathrm{CM} 3 / \mathrm{MOL} . / / / / /)$ WRITE OUTPUT TAPE $9,7,111 \mathrm{~A}, 11 \mathrm{R}, \mathrm{P}$

7 FORMAT $(6 X, 11$ HOUTPUT DATA///6X,19HFUEL DISPLACEMENT =, E $12.4,6 \mathrm{X}$, 
128 HINNER COATING DISPLACEMENT $=$, E $12.4,6 \mathrm{X}, 1$ OHPRESSURE $=$, E $12.4,1 \mathrm{X}$, 2.3HPSI///)

WRI TEOUTPUTTAPE 9,8

8 FORMAT $(10 \mathrm{X}, 2.3 \mathrm{HZ}=$ FRACTIONAL DISTANCE, 8X,9HE THETA $=, 16 \mathrm{X}$,

115 HSIGMA THETA $N=, 10 X, 13$ HSIGMA THETA $=/ 10 \mathrm{X}, 14$ HACROSS COATING, 17X, 2.17HTANGENTIAL. STRAIN, 8X,17HTANGENTIAL STRESS, 8X,17HTANGENTIAL STRE 3SS/41X,10HFRACTIONAI., 15X, 1OHNORMAL IZED, 15X, 3HPSI//)

WRI TEOUTPUTTAPE $9,9,(Z(1), E T(N, 1), \operatorname{SIGTN}(N, 1), \operatorname{SIGT}(N, 1), 1=1,11)$

9 FORMAT(F21.1,F32.6,F2.5.6,F2.2.0)

C

C REPEAT FOR NEW CASE

C

$\mathrm{N}=\mathrm{N}+1$

IF (N-NC) 1, 1,50

50 IF(LP) $52,5.2,51$

51 CALL. PLOTS( PL.TARRAY, 2500,8 )

C

C

DRAW AND LABEL AXES

C

$M=0$

$X M=0$.

$80 X=0$.

$X$ LABEL $=0.0$

DO $60 \mathrm{~J}=1,6$

CALI. NUMBER(X-0.16,0.8,0.14, XLABEL. , 0. 4HF.3.1)

CALI. PI.OT $(X, 1,3)$

CALI. $P L . O T(X, 1,1,2)$

$X=X+1.0$

$60 \times L A B E I .=X I . A B E L+0.2$

CALI. PI.OT $(X M+5,, 1,3)$

CALL. PI.OT $(X M, 1,2)$

CALI. SYMBOI. (XM+0.48,0.5,0.14,34HFRACTIONAL DISTANCE ACROSS COATING $1,0 ., 34)$

CALI. PI.OT $(X M+5,, 1,3)$

CALL PI.OT(XM+5.,9.5, 2.) 
CALI. PL.OT $(X M, 9.5,1)$

CALI. PLOT $(X M, 1,1)$

YI.ABEL $=-0.015$

$Y=1.5$

DO $61 \mathrm{~K}=1,9$

CALL. NUMBER(XM- $.66, Y-.07, .14, Y L A B E L ., 0 。 4 H F 5.3)$

CAL1. PLOT $(X M, Y, 3)$

CALL PL.OT $(X M+.1, Y, 2$.

$Y=Y+1.0$

$61 Y L_{. A B E L}=Y I_{. A B E .}+0.005$

CALI. PI.OT $(X M, 4.5,3)$

CALI. PI.OT $(X M+5 ., 4.5,2$.

IF $(M) 70,70,71$

70 CALI. SYMBOL (XM-0.84,3.09, 14,28HTANGENTIAL STRAIN IN COATING,90., 128)

C

C

C

DO 82. $\mathrm{N}=1, \mathrm{NC}$

DO $81 \quad l=1,11$

$X=X M+5 *$ * $(1)$

$\mathrm{Y}=4.5+2.00 . * \mathrm{E} . \mathrm{T}(\mathrm{N}, 1)$

CALI. PL.OT $(X, Y, 3)$

NUM $=N$

81 CALL SYMBOI. $(X, Y, 0.08$, NUM, $0,,-1)$

IF (LABC) $82,185,186$

185 CALL. SYMBOL $(X M+.5,9.0, .07,15$ HDELTA T (DEG C), $0 ., 15$ )

SNO $=\mathrm{N}-1$

SYML.OC $=9.04-.2 *$ SNO

CALL SYMBOL. $(X M+1.6$, SYML.OC $, .08, N U M, 0 .,-1)$

CALI. NUMBER(XM+1 .75, SYML.OC, $-.04, .07$, L.DELT(N), 0, 2H15)

GO TO 82.

186 CALL SYMBOL. (XM+.5,9.0,.07,17HBURNUP (PER CENT),0.,17)

$S N O=N-1$

SYMLOC $=9.04-.2 *$ SNO 
CALI. SYMBOL. ( XM+1.7, SYML.OC, .08, NUM, 0.,-1)

CALL. NUMBER(XM+1 .85, SYMLOC. $-.04, .07$, BURN(N),0.,4HF3.1)

82. $M=M+1$

CALL PI.OT $(10,1,-3)$

GO TO 80

71 CALI. SYMBOI. (XM-.84, $2.93, .14,39$ HNORMALIZED TANGENTIAL STRESS IN COA 1 TING, 90.,39)

C

C

C

PLOT NORMAL.IZED STRESS PROFILES

DO $84 \mathrm{~N}=1, \mathrm{NC}$.

DO $83 \quad I=1,11$

$X=X M+5 * Z(1)$

$Y=4.5+2.00 * \operatorname{SIGTN}(N, 1)$

CALL $\operatorname{PI.OT}(X, Y, 3)$

NUM $=N$

83 CALL SYMBOL $(X, Y, .08$, NUM, $0 .,-1)$

IF (LABC) $84,285,286$

285 CALL SYMBOL $(X M+.5,9.0, .07,15$ HDELTA T (DEG C), $0 ., 15)$

$\mathrm{SNO}=\mathrm{N}-1$

SYMLOC $=9.04-.2 *$ SNO

CALI. SYMBOL. ( XM+1 .6, SYML.OC, .08, NUM, 0.,-1)

CALI. NUMBER(XM+1 .75, SYMLOC, $-.04, .07$, L.DELT(N), 0.,2HI5)

GO TO 84

286 CALL. SYMBOL. (XM+.5,9.0,.07,17HBURNUP (PER CENT), 0.,17)

$S N O=N-1$

SYML_OC $=9.04-.2 *$ SNO

CALL. SYMBOL. $(X M+1.7$, SYML.OC, .08, NUM, 0., -1)

CAL.L NUMBER(XM+1 .8. , SYMI.OK.-.04, .07, BIIRN(N),0. 4HF3.1)

84 CONTINUE

CALI. PI.OT $(10,, 1,-3)$

52. $N T=N T+1$

IF(NT-NTT) 201,201,53

53 CALL EXIT

END STRETCH 


\section{Appendix E}

\section{REPRODUCTION OF COMPUTER PRINT-OUT SHEET AND NOTATION LIST}

Tabulated results of one of the illustrative calculations are presented in the attached reproduction of a computer print-out sheet. Since Greek letters and subscripts were not available in the print-out the list of notation is modified somewhat from that of the text as follows:

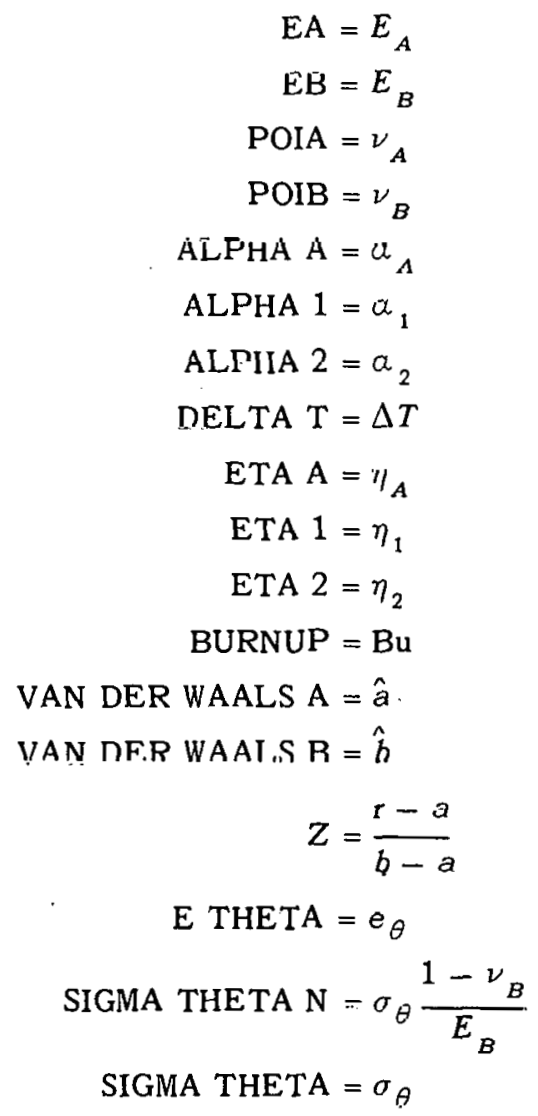

The print-out of certain input quantities in $E$ format may be unfamiliar to some readers. 'The symbolism is a slight modification of standard "power of 10 " notation where $n . n n n E \pm n n n \equiv n . n n n \times$ $10^{\text {tnnn }}$. 
INPUI INEGRMATION CASE NJMBEP I- 2 O30018
$\left.E_{A}=2.9\right] J 0 E+007$ PSI
$E B=2 \cdot[G 0 E+00, P S I$
Po14 $=.300$
POIB $=.250$
A 10 B RATLO $=.52500$

ALDTA A $=1.5800 t-005 / \mathrm{C}$

ALPHA I $=1 ., 5 \pi 0: 0$ DOO/C

ALPHA $2=\angle .2000 E-1005 / C$

DELTAT $=400 \mathrm{C}$

ETA $A=.0000-1300$

FTA $1=.00 C U E+D U T$

ETA $2=.00 N J E+U O D$ RURNUP $=$.U PER CENT

COAIING INNEIS ZADIUS $=1.0500 E-002 \mathrm{cM}$

INTITIAL GAP $=5$. OUOUE-OLU CM

GAP POROSITY $=1.000$

MO_S HF FISSION GAS $=$, ODODE+00O

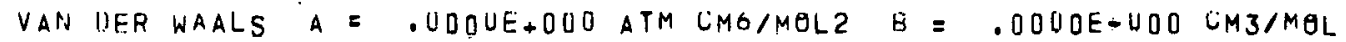

QUTPUT UA-A

FUFL DISPLACEMENT $=\$ .32$ UEE-003

IANER CHATING DISPLACEMENT $=-2.9579 E-00 \mathrm{~S}$

E THEFA =
I DNFENTIAL STHAIN
! RACTIGMAL

SIGMA THETA N =
TANGENTIAL. STRFSS

NORMALI LED

$-.003478$

$\because .002524$

$-.001743$

$-.001085$

$-.00051 ?$

$-.000017$

.000429

, $0 \cup 0832$

.001201

.001541

.001857
PRESSURF $=.0000 E+000$ PSI

SIGMA THETA =

TANGENTIAL STREOS

PS I 


\section{NOTATION}

\section{Upper Case}

$A_{1} \quad$ Parameter group defined in Eqs. (27) and (27a)

$A_{2}$ Parameter group defined in Eqs. (28) and (28a)

$\bar{A}_{1} \quad$ Parameter group defined in Eqs. (35), (35a), and (40)

$\bar{A}_{2}$ Parameter group defined in Eqs. (36), (36a), and (41)

$\mathrm{Bu}$ Percent burnup of fuel atoms (including both fissile and fertile materials), 100 (atoms fissioned)/(atoms initially present)

$C_{1}, C_{2}, C_{3}$ Constants of integration, arising in solutions of differential equations (20) and (42)

$E_{A}$ Young's modulus for fuel core

$E_{B}$ Young's modulus for coating (directional average)

$E_{1}$ Young's moduli for coating material in parallel crystal direction

$E_{2}$ Young's modulus for coating material in perpendicular crystal direction

$F_{1}-F_{6}$ Functions of radial position in coating defined in Eqs. (56) through (61)

$G_{1}, G_{2}$ Anisotropic expansion functions defined in Eqs. (18) and (19)

$M_{i}$ Atomic or molecular weight of substance $i$

$P$ Gas pressure in gap between fuel and coating

$R$ Gas constant

$T$ Temperature at a point in a coated particle

$T_{a}$ Temperature at inner surface of coating

$T_{b} \quad$ Temperature at outer surface of coating

$T_{c}$ Temperature at which coating was applied to particle

$T_{f}$ Temperature at outer surface of fuel core

$T_{g} \quad$ Average absolute temperature in gap between fuel and coating

$T_{\text {。 }}$ Temperature at center of fuel core

$U_{1 A}$ Fractional outward displacement of outer fuel surface, (total displacement)/(initial fucl radius)

$U_{1 B}$ Fractional outward displacement of inner coating surface, (total displacement)/(initial inner coating radius)

$U_{10}$ Displacement parameter defined by Eqs. (39) and (39a)

$V_{f}$ Volume of fuel core

$V_{G} \quad$ Volume of gas in gap between fuel and coating

$V_{s}$ Volume of solid material in gap between fuel and coating

$W$ Power generation rate in fuel core, (energy)/(time)

$X_{i}$ Mass fraction of atomic species $i$ in fuel material

\section{Lower Case}

a inner radius of coating

$a_{f}$ fuel core outer radius 
$a_{1}, a_{2}, a_{3}$ Elastic constant groupings defined in Eqs. (15), (16), and (17)

$\hat{a}$ Constant in van der Waals equation of state

$b$ Outer radius of coating

$\hat{b}$ Constant in van der Waals equation of state

$e_{\theta}$ Normal strain in tangential direction

e. Normal strain in radial direction

$f$ Fraction of total gaseous fission products released from fuel core, (atoms released)/ (atoms formed)

6 Fractional linear expansion in fuel core from all causes

$\bar{g}_{A} \quad$ Average expansion term for fuel core, defined in Eq. (45)

$g_{R}$ Isotropic fractional linear expansion in coating

$\bar{g}_{B} \quad$ Average isotropic expansion term for coating, defined in Eq. (62)

$g_{1}$ Fractional linear expansion in parallel crystal direction from all causes

$g_{2}$ Fractional linear expansion in perpendicular crystal direction from all causes

$k_{f}$ Thermal conductivity of fuel core

$k_{g}$ Thermal conductivity of gap between fuel and coating

$k_{s} \quad$ Thermal conductivity of coating material in radial direction

$n_{1}, n_{2}$ Constants defined in Eq. (24)

$M_{G} \quad$ Moles of fission gas in gap between fuel and coating

$r$ Radial position in coated particle measured from center of fuel core

$s_{i j}$ Elastic compliance constant, relating strain component $i$ to stress component $j$; see Eqs. (2) and (3)

$t$ Equivalent thickness of solid material in gap between fuel and core; see Eq. (67)

$u$ Outward radial displacement of a point in coated particle

$u_{c}$ Complementary solution to Eq. (20)

$y$ Initial width of gap between fuel and coating

\section{Lower Case Greek}

$\begin{array}{cl}a_{A} & \text { Thermal cxpansion coefficient of fuel core } \\ a_{1} & \text { Thermal expansion coefficient of coating in parallel crystal direction } \\ a_{2} & \text { Thermal expansion coefficient of coating in perpendicular crystal direction } \\ \gamma & \text { Parameter group defined by Eq. (51) or (51a) } \\ \gamma_{G} & \text { Total yield of gaseous fission products, (gas atoms produced)/(fission) } \\ \epsilon_{\theta} & \text { Total fractional elongation in the tangential direction; see Eqs. (7) and (9) } \\ \epsilon_{r} & \text { Total fractional elongation in the radial direction; see Eqs. (8) and (10) } \\ \eta_{A} & \text { Fractional linear expansion of fuel core produced by radiation } \\ \eta_{1} & \text { Fractional linear expansion of coating in the parallel crystal direction pro- } \\ & \text { duced by radiation }\end{array}$


$\eta_{2} \quad$ Fractional linear expansion of coating in the perpendicular crystal direction produced by radiation

$\theta \quad$ Angle representing tangential position in sphere

$\nu_{A} \quad$ Poisson's ratio for fuel core

$\nu_{B}$

Average Poisson's ratio for coating material

Poisson's ratio for coating, relating contraction in the parallel layer planes to elongation at right angles but also in the parallel layer planes

Poisson's ratio, relating contraction in the parallel crystal layer planes to elongation in the perpendicular direction

$\nu_{3} \quad$ Poisson's ratio, relating contraction in the perpendicular crystal direction to elongation in the parallel layer planes

$P_{f} \quad$ Fuel core density

$\sigma_{\theta} \quad$ Normal stress in the tangential direction

$\sigma_{r} \quad$ Normal stress in the radial direction

$\phi \quad$ Open porosity of gap between fuel core and coating, (gas volume)/(total gap volume); or, where appropriate under existing convention, the angle representing polar position in sphere (indistinguishable trom $\theta$ in present work due to symmetry)

Thermal neutron flux in coated particle, neutrons $\mathrm{cm}^{-2} \mathrm{sec}^{-1}$ 
ORNL.3553

UC-25 - Metals, Ceramics, and Materials TID.4500 (29th ed.)

INTERNAL DISTRIBUTION

1-3. Central Research Library

4. Reactor Division Library

5-6. ORNL - Y-12 Technical Library, Document Reference Section

7-26. Laboratory Records Department

27. Laboratory Records, ORNL R.C.

28. R. E. Adams

29. E. S. Bomar

30. C. M. Blood

31. F. L. Carlsen, Jr.

32. J. L. Cook

33. D. R. Cuneo

34. J. E. Cunningham

35. D. A. Douglas

36. W. S. Ernst, Jr.

37. J. H Frye, Jr.

38. W. R. Gall

39. B. L. Greenstreet

40. W. O. Harms

41. H. L. Hemphill

42-46. M. R. Hill

47. G. W. Keilholtz

48. C. E. Larson

49. H. G. MacPherson
50. H. A. McLain

51. F. R. McQuilkin

52. S. E. Moore

53. J. G. Morgan

54. F. H. Neill

55-56. R. B. Parker

57-61. J. W. Prados

62. S. A. Rabin

63. M. W. Rosenthal

64. G. Samuels

65-89. J. L. Scott

90. M. J. Skinner

91. O. Sisman

92. C. O. Smith

93. Albert Spaller

94. J. A. Swartout

95-133. D. B. Trauger

134. J. R. Weir

135. A. M. Weinberg

136. F. J. Witt

137. A. A. Burr (consultant)

138. J. R. Johnson (consultant)

139. C. S. Smith (consultant)

140. R. Smoluchowski (consultant)

\section{EXTERNAL DISTRIBUTION}

141. W. L. Rice, AEC, Wuslininglon

142. J. M. Simmons, AEC, Washington

143. D. K. Stevens, AEC, Washington

144. M. A. DeCrescente, Pratt and Whitney

145. T. Pashos, General Electric, APED, San Jose

146. D. E. Baker, General Electric, Hanford

147. E. Evans, General Electric, Hanford

148. H. C. Brassfield, General Electric, Cincinnati

149. B. Weideuboum, General Electric, APED, San Jose

150. D. R. DeHalas, General Electric, Hanford

151. W. E. Roake, General Electric, Hanford

152. W. Francis, Phillips Petroleum Company

153. A. Shoudy, Atomic Power Development Association

154. D. V. Ragona, General Atomic

155. J. F. Watson, General Atomic 
156. C. E. Weber, Atomics International

157. B. R. Hayward, Atomics International

158. F. A. Rough, Battelle Memorial Institute

159. J. H. Kittel, Argonne National Laboratory

160. A. Boltax, Westinghouse-Astronuclear

161. W. K. Barney, Knolls Atomic Power Laboratory

162. A. Strasser, United Nuclear Corporation

163. M. L. Bleiberg, Bettis Atomic Power Laboratory

164. J. A. Brinkman, North American Aviation Science Center

165. J. A. Leary, Los Alamos Scientific Laboratory

166. D. Gurinsky, Brookhaven National Laboratory

167. C. M. Adams, Jr., Massachusetts Institute of Technology

168. J. L. Gregg, Cornell University

169. E. E. Stansbury, University of Tennessee

170. L. M. Slifkin, University of North Carolina

171. Ressearch and Development Division, AEC, ORO

172-745. Given distribution as shown in TID-4500 (29th ed.) under Metals, Ceramics, and Materials category (75 copies - OTS) 